BNL 52384

(REV. 10/96)

UC-406

\title{
THERMAL DEGRADATION OF CONCRETE IN THE TEMPERATURE RANGE FROM AMBIENT TO $315^{\circ} \mathrm{C}\left(600^{\circ} \mathrm{F}\right)$
}

M.K. Kassir, K.K. Bandyopadhyay and M. Reich

OCTOBER 1996

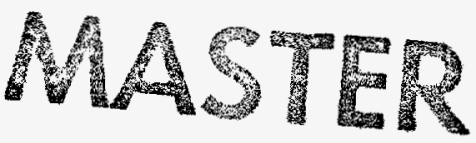

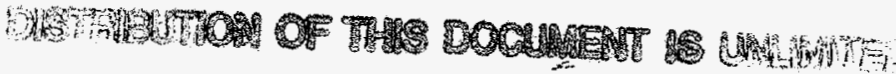

ENGINEERING RESEARCH AND APPLICATIONS DIVISION DEPARTMENT OF ADVANCED TECHNOLOGY

BROOKHAVEN NATIONAL LABORATORY, ASSOCIATED UNIVERSITIES, INC. UPTON, NEW YORK 11973-5000

Prepared for the

OFFICE OF ENVIRONMENTAL RESTORATION AND WASTE MANAGEMENT UNITED STATES DEPARTMENT OF ENERGY, WASHINGTON, D.C.

CONTRACT NO. DE-AC02-76CH00016 


\section{DISCLAIMER}

Portions of this document may be illegible in electronic image products. Images are produced from the best available original document. 


\section{DISCLAIMER}

This report was prepared as an account of work sponsored by an agency of the United States Government. Neither the United States Government nor any agency thereof, nor any of their employees, make any warranty, express or implied, or assumes any legal liabiity or responsibility for the accuracy, completeness, or usefulness of any information, apparatus, product, or process disclosed, or represents that its use would not infringe privately owned rights. Reference herein to any specific commercial product, process, or service by trade name, trademark, manufacturer, or otherwise does not necessarily constitute or imply its endorsement, recommendation, or favoring by the United States Government or any agency thereof. The views and opinions of authors expressed herein do not necessarily state or reflect those of the United States Government or any agency thereof. 


\section{ABSTRACT}

This report is concerned with determining the effect of elevated temperatures on the behavior of concrete. Emphasis is placed on quantifying the degree of potential degradation of the physical properties of concrete in high-level waste storage tanks. The temperature elevation range of interest is from ambient to $315^{\circ} \mathrm{C}\left(600^{\circ} \mathrm{F}\right)$. The literature has been reviewed to examine the applicable experimental data and quantify the degradation in the concrete and reinforcing steel. Since many variables and test conditions control the results in the data base, upper and lower bounds of the degraded properties at temperatures applicable to the environments of the storage tanks are summarized and presented in explicit forms. For properties with large data bases, a normal logarithmic distribution of the data is assumed and a statistical analysis is carried out to find the mean and $84 \%$ values of the degraded property in the temperature range of interest. Such results are useful in assessing the effect of elevated temperatures on the structural behavior of the tanks. In addition, the results provide the technical basis for a parametric study that may be necessary to investigate the thermal aspects of the structural integrity of the tanks.

The original version of this report was published in June 1993. Since then additional test data of concrete properties at elevated temperatures, especially creep strain, have been added to the data base. This version of the report incorporates the statistical variations of those concrete properties for which significant amounts of experimental data have been reported. In addition, an empirical formula relating the creep strains at elevated temperatures to those at ambient temperture is provided. 

TABLE OF CONTENTS

PAGE

Abstract

Table of Contents

List of Figures.

List of Tables

Executive Summary

Acknowledgement.

1.0 Introduction

2.0 Mechanical and Physical Properties . . . . . . . . . . 2

2.1 Compressive strength . . . . . . . . . . . . . . . 3

2.2 Tensile strength . . . . . . . . . . . . . . . 4

2.3 Stiffness (Modulus of Elasticity) . ... . . . . . . 7

2.4 Poisson's Ratio..................... . 7

2.5 Stress-strain Relations... . . . . . . . . 7

2.6 Creep . . . . . . . . . . . . . . . . . . . 9

2.6.1 Creep at temperatures below $121^{\circ} \mathrm{C}\left(250^{\circ} \mathrm{F}\right) \cdot 14$

2.6 .2 Creep at temperatures above $121^{\circ} \mathrm{C}\left(250^{\circ} \mathrm{F}\right) \cdot 20$

2.6.3 Thermal scaling factor. . . . . . . . . 26

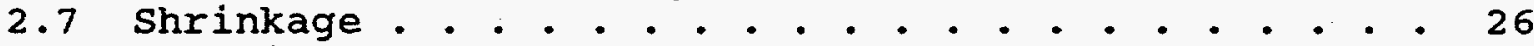

2.8 Coefficient of Thermal Expansion . . . . . . . . . 27

2.9 Thermal Conductivity . . . . . . . . . . . . . 27

2.10 Thermal Diffusivity . . . . . . . . . . . . . . 28

2.11 Specific Heat . . . . . . . . . . . . . . 28

3.0 Effect of Elevated Temperature on Reinforcing Steel . . 28

3.1 Yield strength . . . . . . . . . . . . . 28

3.2 Modulus of Elasticity . . . . . . . . . . . . 30

3.3 Coefficient of Thermal Expansion . . . . . . . . 30

3.4 Thermal Conductivity and Thermal Diffusivity . . . 30

4.0 Bond strength . . . . . . . . . . . . . . . . 30

5.0 Thermal Cycling . . . . . . . . . . . . . . . . 33

6.0 Effect of Long-Term Exposure . . . . . . . . . . . . 37

7.0 summary . . . . . . . . . . . . . . . . . . . . 37

8.0 References . . . . . . . . . . . . . . . . . . 41 


\section{IIST OF FIGURES}

Figure

Page

1 Reduction of compressive strength of concrete at Elevated Temperatures

2 Reduction of Tensile strength of Concrete at Elevated Temperatures

3 Reduction of the Modulus of Elasticity of Concrete at Elevated Temperatures . . . . . . . . . . . . . 8

4 Stress-strain Diagrams of Limestone Aggregate Concrete . 10

5 Stress-strain Behavior of Lightweight Aggregate Concrete . . . . . . . . . . . . . . . . . . 11

6 Typical Stress-strain Diagrams for Modeling Concrete . . 12

7 Effect of Aggregate Modulus on Creep of Concrete at Ambient Temperature . . . . . . . . . . . . . . 13

8 Variation of Total Strain with Time at Elevated Temperature . . . . . . . . . . . . . . . . 15

9 Variation of Total Strain with Time at $68^{\circ} \mathrm{F}\left(20^{\circ} \mathrm{C}\right)$ and

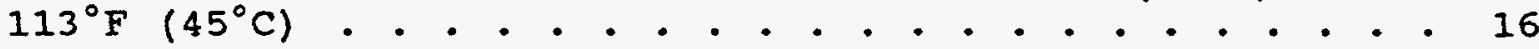

10 Variation of Creep Strain Per Unit Applied stress with Time . . . . . . . . . . . . . . . . . . 18

11 Variation of Total Strain Per Unit Applied stress with Time . . . . . . . . . . . . . . . . . . 21

12 Variation of creep Strain per Unit Applied Load with Time . . . . . . . . . . . . . . . . . . .

13 Variation of Creep Strain Per Unit Applied Load with Time . . . . . . . . . . . . . . . . . 24

14 Creep Function of Different Concretes Appearing in Equation (2) . . . . . . . . . . . . . . . 25

15 Variation of Specific Heat with Temperature . . . . . . 29

16 Influence of Temperature on Modulus of Elasticity of Different Reinforcing steels . . . . . . . . . . .

17 Bond strength of Concrete at $0.050 \mathrm{~mm}(0.002 \mathrm{in.)}$ Slippage of Free End 


\section{IIST OF FIGURES (Continued)}

Figure

Page

18 Effect of Thermal Cycling on Unsealed Limestone concrete... . . . . . . . . . . . . . . . 34

19 Effect of Thermal Cycling and sustained Temperatures on Sealed Limestone Concrete . . . . . . . . . . . 35

20 Effect of Thermal Cycling on Sealed Limestone Aggregate Concrete... . . . . . . . . . . . . 36

21 Variation of Residual Compressive strength with Temperature and Age . . . . . . . . . . . . . . 38

22 Variation of Modulus of Elasticity with Temperature and Age . . . . . . . . . . . . . . . . . 39

23 Effect of Duration of Exposure on Compressive Strength of Limestone and Dolostone Concretes . . . . . . . . . . 40 


\section{LIST OF TABLES}

Table

Page

1 Thermal scaling Factors at Temperatures Below $121^{\circ} \mathrm{C}\left(250^{\circ} \mathrm{F}\right)$. . . . . . . . . . . . . . . . 17

2 Thermal Scaling Factors at Elevated Temperatures

After 7 Days of Loading 


\section{EXECUTIVE BUMMARY}

The compressive and tensile strengths and modulus of elasticity of concrete tend to decrease when concrete is subjected to elevated temperatures. Also, repeated thermal cycling causes an increase in the nonrecoverable maximum strain, and could affect the bond strength between the concrete and the steel reinforcement. other mechanical and physical properties of concrete are also degraded because of the exposure to elevated temperatures. Undoubtedly, such degradation could have a strong impact on the structural behavior of those waste storage tanks that have been subjected to high temperatures during their service lives.

The objective of this study is to provide a quantitative interpretation of the concrete degradation for the high-level waste storage tanks subjected to elevated temperatures. Since the wastes in many tanks are reported to have achieved a temperature range of $150-180^{\circ} \mathrm{C}\left(302-356^{\circ} \mathrm{F}\right)$, and in a few tanks the temperature is suspected of having reached $200-315^{\circ} \mathrm{C}\left(392-600^{\circ} \mathrm{F}\right)$, attention is focused on quantifying the effects of temperature increases from ambient to the $315^{\circ} \mathrm{C}\left(600^{\circ} \mathrm{F}\right)$ level.

An independent literature review of the laboratory test data has been undertaken and the applicable degradation in the mechanical and physical properties of concrete is examined and quantified. These properties include compressive strength, tensile strength, modulus of elasticity, Poisson's ratio, time-dependent properties (creep and shrinkage), thermal properties (expansion, conductivity, diffusivity, and specific heat), thermal cycling and characteristics of the stress-strain relation. The influences of elevated temperature on the yield strength, modulus of elasticity, and thermal properties of the reinforcing steel as well as the bond strength between concrete and steel are also discussed. Because many variables and test conditions govern the test data, upper and lower bounds of the degraded properties are provided. For properties with large data bases (e.g., for the compressive strength and modulus of elasticity), a log-normal distribution of the data is assumed and an analysis is carried out to provide the mean and $84 \%$ values of the physical properties. The results are useful for assessing the structural response of the storage tanks that were exposed to elevated temperatures. The threshold of significant degradation of concrete is around $65-93^{\circ} \mathrm{C}\left(150-200^{\circ} \mathrm{F}\right)$. For this reason, current codes and industry standards dealing with reinforced concrete structures specify a maximum temperature limit of about $65-93^{\circ} \mathrm{C} \quad\left(150-200^{\circ} \mathrm{F}\right)$ to ensure predictable concrete behavior. Potential degradation beyond this temperature range needs to be considered for structural evaluation. 
The authors would.like to acknowledge the effort of Dr. Bryant Mather, Director, structures Laboratory, Waterways Experiment Station, Corps of Engineers, Department of the Army, for reviewing the manuscript and providing valuable comments. The authors are grateful to Drs. Howard Eckert, Dinesh Gupta and Kenneth Lang, DOEEM, for support, advice and encouragement. 


\subsection{INTRODUCTION}

The concrete vaults of the high-level waste storage tanks have been exposed to sustained high temperatures for a long period due to decay heating of the wastes stored in the tanks. The wastes were produced as a result of chemical processing of nuclear materials. The wastes in many tanks are reported to have achieved a temperature range of $150-180^{\circ} \mathrm{C}\left(302-356^{\circ} \mathrm{F}\right)$. The waste temperatures in a few tanks are suspected of having attained an even higher range of $200-315^{\circ} \mathrm{C}\left(392-600^{\circ} \mathrm{F}\right)$. It is well known that concrete materials degrade at elevated temperatures. The purpose of this report is to discuss the results of a literature search and present generic bounding experimental data that can be used to verify the structural integrity of the concrete components in the waste storage tanks. In order to provide an independent verification, the limited test data that exist for waste storage tanks are not included in the current study.

When conventional concrete is exposed to elevated temperatures, it begins to experience dehydration reactions in the hydrated cement paste, possible thermal incompatibilities between paste and aggregate, and eventual physiochemical deterioration of the aggregate. Typically, such degradation is accompanied by a decrease in the compressive strength, and in the stiffness (modulus of elasticity) of the concrete. In the temperature range of interest for the waste storage tanks, very little degradation is expected to occur in the mechanical properties of the steel reinforcement. The stress-strain curve for concrete is also influenced by the rise in temperature. Moreover, repeated thermal cycling due to fluctuating temperatures reduces the peak strength and could loosen the bond between the concrete and the reinforcing bars. The thermal gradients and induced thermal stresses could trigger microcracking, crumbling and spalling of the concrete, and depending on the available cover, could expose the embedded reinforcing steel.

This study quantifies the influence of a rise in temperature from ambient to $315^{\circ} \mathrm{C}\left(600^{\circ} \mathrm{F}\right)$ on the mechanical and physical properties of the concrete. The results can be used to estimate the influence of high temperature on the structural behavior and integrity of concrete components. The properties investigated for this purpose include compressive and tensile strengths, stiffness, time-dependent properties (creep and shrinkage), thermal expansion, thermal conductivity, thermal diffusivity, specific heat and characteristics of the stress-strain relations. These parameters are the principal ones by which the structural behavior of reinforced concrete can be judged. They provide the technical basis for numerical modeling and structural integrity analysis of a concrete tank. The compressive strength affects the loadcarrying capacity of a structural component while the stiffness influences the deformation and load distribution. For the small strain analysis of concrete structures, a knowledge of the strength 
and the elastic modulus is sufficient. However, when large strains are involved, as in a structural integrity analysis, a knowledge of the stress-strain relationship of the concrete at elevated temperatures is also required.

An independent literature review has been undertaken for this purpose and the applicable manifestations of degradation are quantified. When there is doubt about the direct applicability of a given set of experimental data to the tank analysis, lower bound estimates of the degradation are made for the sake of conservatism. When the experimental data base of a physical property is large, a statistical analysis is carried out to determine the mean and $84 \%$ values of the property assuming log-normal distribution of the data. The results are summarized in the following sections.

\subsection{MECHANICAL AND PHYSICAL PROPERTIES}

The significant mechanical properties of concrete (compressive and tensile strengths and stiffness) are generally degraded when concrete is exposed to elevated temperatures. Experimental data supporting such degraded behavior of concrete have been extensively studied in the literature (References 1-30). The level of degradation is influenced by many variables including concrete mixing, curing age before exposure to heat, and test conditions. The primary conditions include the following:

- Conditions of testing: whether the concrete is tested while hot or after cooling; whether it is quenched or allowed to cool slowly before testing.

- Conditions of loading during specimen heating: whether the concrete specimen is restrained during heating.

- Moisture content of concrete when heated.

- Prevention of moisture loss: whether free moisture is contained (sealed specimen) or allowed to evaporate during heating (unsealed specimen).

- Specifics of concrete mixture proportions, specimen size, degree of curing, and length of time the specimen was heated and allowed to stabilize before load testing.

Physical properties of concern to the behavior of concrete at elevated temperatures are thermal expansion, thermal conductivity, thermal diffusivity, and specific heat. These properties determine the nature of the heat transfer through the concrete and, as a consequence, affect its load bearing and load transfer capabilities.

Comprehensive reviews of the effects of elevated temperatures, ambient to about $982^{\circ} \mathrm{C}\left(1800^{\circ} \mathrm{F}\right)$, on concrete used in nuclear power plant structures and components are available in References 26 and 
30. These review documents also contain a list of the original references in which the actual specimen test data were published. Additional data which include experimental studies on the behavior and ultimate strengths of actual concrete structural members when subjected to elevated temperatures are available in References 31 and 32. Various aspects of creep and shrinkage of concrete at elevated temperatures are examined in References 7, 15, 27 and 33 to 45. The effects of elevated temperatures on the properties of reinforcing steel are discussed in References 21 and 27. Experimental data on the bond strength between concrete and reinforcing steel at elevated temperatures are given in References 46 to 48 . Effects of long term exposure of concrete to elevated temperatures are discussed in References 49 and 50.

A review of the laboratory data base indicates that concrete specimens of many sizes and shapes were heated for varying periods and temperatures and tested using many of the variables and conditions mentioned above. The test conditions which can have the most influence on the degradation of concrete in the present application are the "cold" and "hot" test conditions. In "cold tests," the specimens are heated to the specified temperature, allowed to stabilize at that temperature for a prescribed time, cooled down slowly to room temperature, and then tested to determine the mechanical properties. In "hot tests," the specimens are gradually heated to the specified level, allowed to stabilize at that level for a prescribed time and then tested while hot at that temperature. The period of sustained heating, the level of temperature rise, and the age of the specimen can substantially affect the degree of degradation. other contributory factors influencing the degradation are concerned with the moisture path during the testing. The specimens in the data base are tested in either an open environment (unsealed specimen) where moisture can escape to the atmosphere or a closed environment (sealed specimen) where moisture is contained. The influence of elevated temperatures, ambient to $315^{\circ} \mathrm{C}\left(600^{\circ} \mathrm{F}\right)$, on the properties of concrete including the influence of these parameters is summarized in the following sections.

\section{1 compressive strength}

As mentioned previously, the compressive strength of concrete generally decreases with a rise in temperature. A review of the technical data, based mostly on laboratory testing, reveals the following:

(a) There is less strength degradation in laboratory specimens tested under "hot" conditions compared to those tested under "cold" conditions.

(b) Sealed specimens lose more strength than unsealed ones. This is because the moisture is not allowed to escape during heating and subsequent testing. 
(c) The type of aggregates and mixture proportions influence the degradation in the strength of heated concrete. In particular, lean concrete (low cement content) shows a smaller reduction in the compressive strength than rich concrete. Also, limestone aggregates degrade less than siliceous ones when the specimen is heated. Thus, using high cement content mixtures to fabricate concrete tanks has a negative influence on its degraded strength.

Based on these observations, the variation of the residual compressive strength of concrete with a rise in temperature up to the $315^{\circ} \mathrm{C}\left(600^{\circ} \mathrm{F}\right)$ level is shown in Figure 1. The experimental data were obtained for specimens tested under both cold and hot conditions. The upper and lower bound strength curves represent the full spread of the data base. The variations of the mean and 84\% compressive strengths (based on standard log-normal distribution of the datal with rise in temperature are also shown in Figure 1. It is clear from this figure that the upper bound of the test data indicates almost no reduction in the concrete strength for elevated temperatures through almost $315^{\circ} \mathrm{C}\left(600^{\circ} \mathrm{F}\right)$. The lower bound data, however, indicate a reduced strength for temperatures above $38^{\circ} \mathrm{C}\left(100^{\circ} \mathrm{F}\right)$. For example, for specimens tested at $149^{\circ} \mathrm{C}\left(300^{\circ} \mathrm{F}\right)$, the lower bound reduced strength is $60 \%$ of the initial compressive strength at room temperature while the mean reduced strength is about $85 \%$ of its original value.

\subsection{Tensize strength}

The tensile strength of concrete (which is about $10 \%$ of its compressive strength at room temperature) tends to decrease with exposure to elevated temperatures. Generally speaking, the percent loss in tensile strength is comparable to the corresponding loss in the compressive strength. Figure 2 shows the full range of variations in the residual tensile strengths of concrete with rise in temperature. These reduced strengths are based on experimental data obtained by using either the splitting cylinder or the flexure test method. The data base includes specimens tested under various laboratory conditions, namely, cold and hot testing, sealed and unsealed moisture conditions, thermally cycled specimens, etc. (References 3, 9, 13, and 33). Repeated thermal cycling to a temperature higher than $204^{\circ} \mathrm{C}\left(400^{\circ} \mathrm{F}\right)$ produces a larger reduction in the tensile strength than a single excursion to the same temperature level (Reference 3). This is mainly due to the differential expansion of paste and aggregates during the heating and cooling periods which result in cracking that materially affects the tensile strength of concrete specimens. On the other hand, thermal excursions in the cyclic temperature range of 23-71$23^{\circ} \mathrm{C}\left(73-160-73^{\circ} \mathrm{F}\right)$ showed no significant effect on the splitting strength of concrete tested in the laboratory (Reference 33). At $149^{\circ} \mathrm{C}\left(300^{\circ} \mathrm{F}\right)$ the lower bound tensile strength of concrete is about $75 \%$ of its initial value while the upper bound date show a negligible loss. 


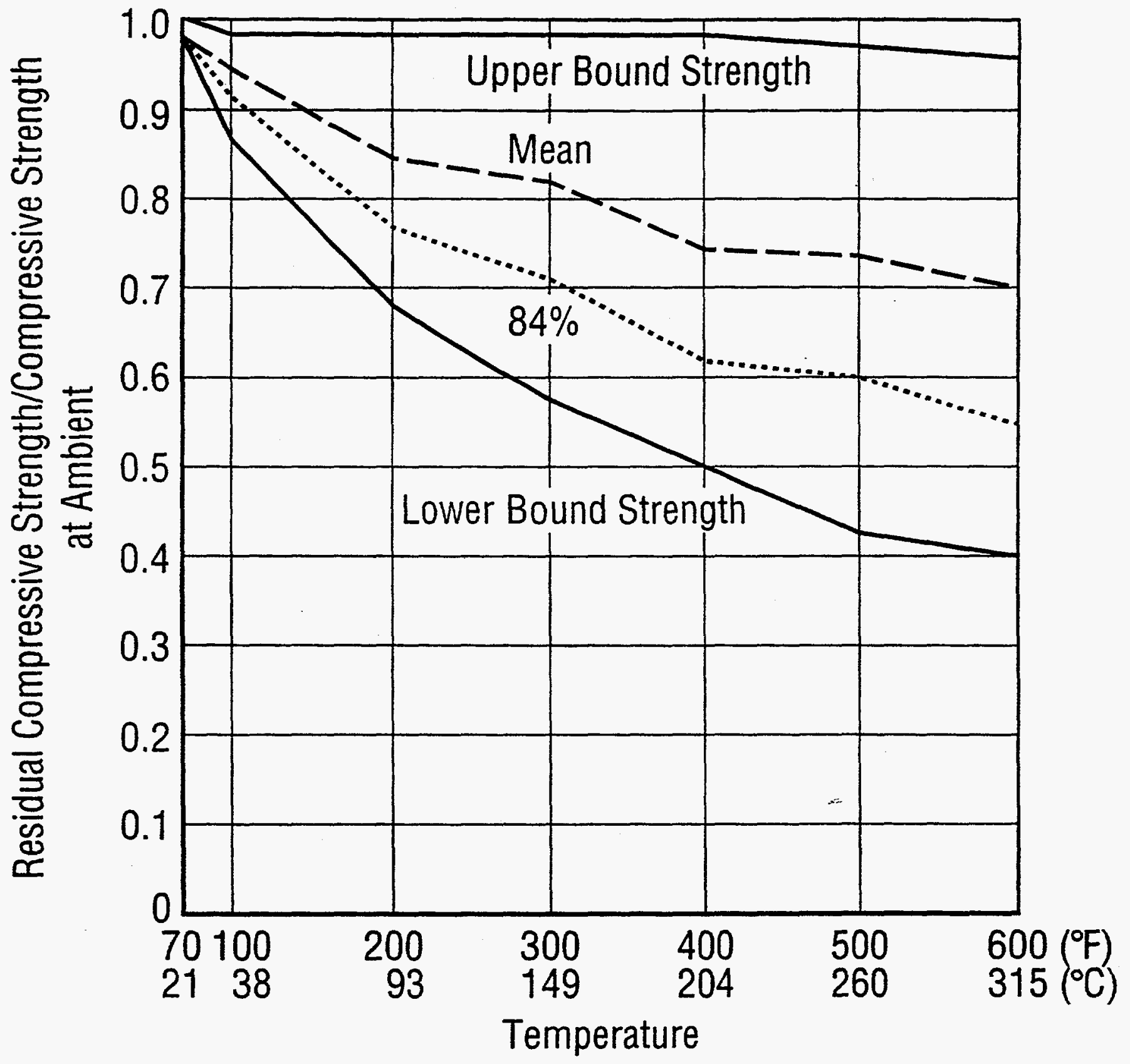

Figure 1 Reduction of Compressive strength of Concrete at Elevated Temperatures 


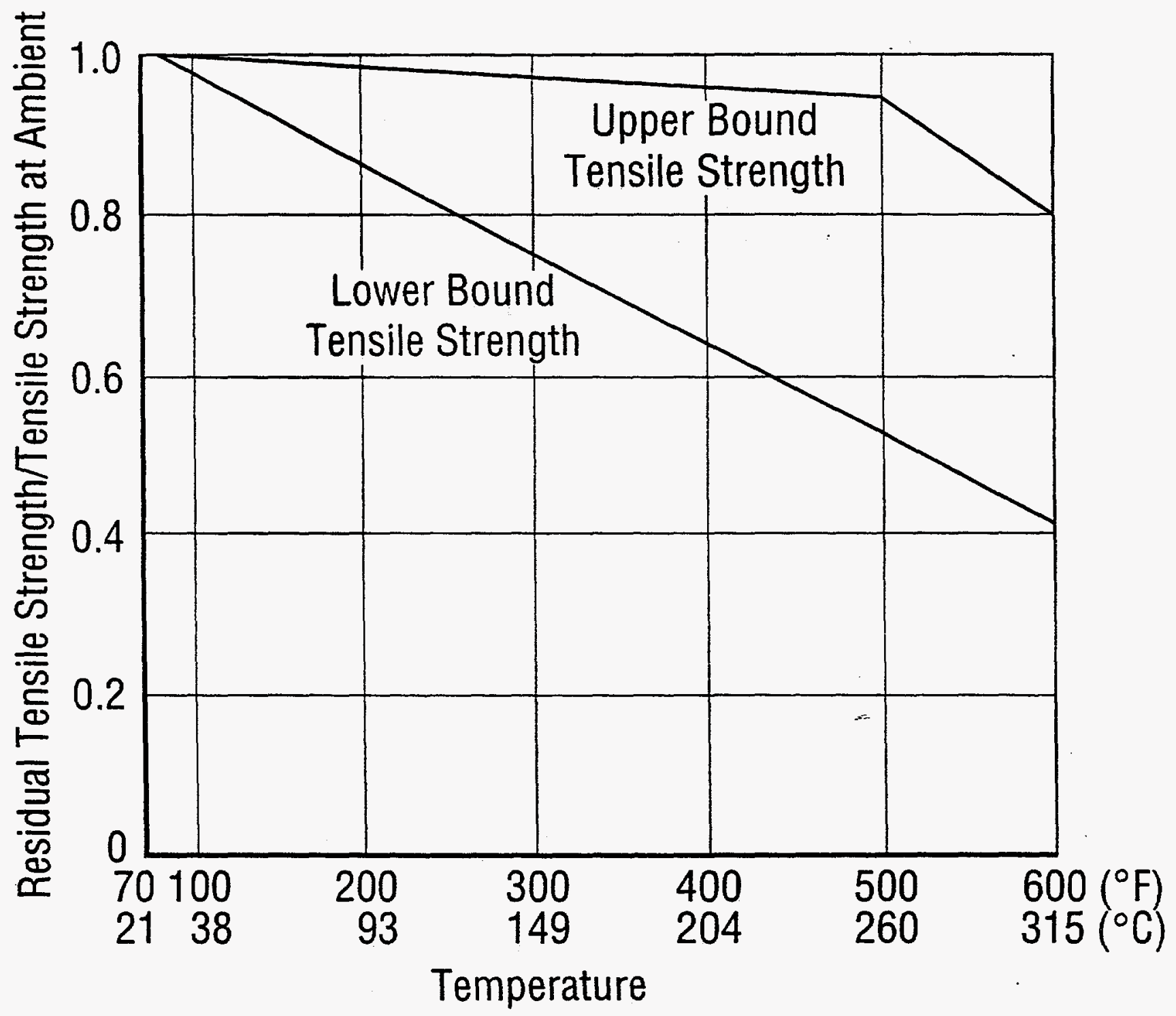

Figure 2 Reduction of Tensile strength of Concrete at Elevated Temperatures 


\subsection{Stiffness (Kodulus of Elasticity)}

The modulus of elasticity, $\mathbf{E}_{c}$, which is the ratio of stress to strain, is an important parameter to describe the structural behavior of concrete components. At elevated temperatures, the modulus experiences a permanent reduction in its value. Like the strength parameter, several factors influence the value of the modulus of elasticity in laboratory specimens tested at high temperatures. The major factors include the method of test conditions (hot or cold) and prevention of moisture loss (sealed or unsealed specimens).

Figure 3 shows the variation of the modulus of elasticity with increase in temperature. The upper and lower curves envelop the data obtained from specimens tested in hot and cold conditions and at various moisture loss conditions. The curves representing the mean and $84 \%$ values of the degraded moduli of elasticity are also shown in Figure 3. At $38^{\circ} \mathrm{C}\left(100^{\circ} \mathrm{F}\right)$, the upper bound envelope indicates no reduction in the modulus while the lower bound curve reveals a reduction of about $5 \%$. At $149^{\circ} \mathrm{C}\left(300^{\circ} \mathrm{F}\right)$, the upper bound curve indicates a reduction of $10 \%$ while the lower bound curve shows a 55\% reduction. This indicates that in the temperature range of concern for the waste storage tanks, the degradation is more pronounced for the stiffness of concrete than the compressive strength. As shown in Figure 3, the reduction in modulus of elasticity at temperatures higher than $149^{\circ} \mathrm{C}\left(300^{\circ} \mathrm{F}\right)$ is significantly greater.

\subsection{Roisson's Ratio}

The variation of Poisson's ratio with elevated temperature can be assessed from axial, flexural and torsional test data. The experimental data, obtained using sealed and unsealed (dry) specimens, indicate a general tendency for Poisson's ratio of concrete to decrease with increasing temperature due to loss of evaporable water in the $\mathrm{mix}$ (References 17 and 18). At $300^{\circ} \mathrm{C}$ $\left(572^{\circ} \mathrm{F}\right)$, the value of Poisson's ratio could be as low as half its original value at room temperature. Thus, Poisson's ratio of concrete reduces from the range of $0.22-0.30$ at room temperature to about $0.13-0.19$ at $300^{\circ} \mathrm{C}\left(572^{\circ} \mathrm{F}\right)$.

\subsection{Stress-strain Relations}

In order to investigate the structural integrity of the waste storage tanks, elastic-plastic analyses resulting in large strains are sometimes required. Thus, in addition to the variation in the modulus of elasticity, one needs to examine the stress-strain characteristics of concrete at the applicable elevated temperature.

The shape of the stress-strain curve of concrete does not change when it is heated. However, because of the induced degradation, the peak in the curve may be reduced and occur at a 


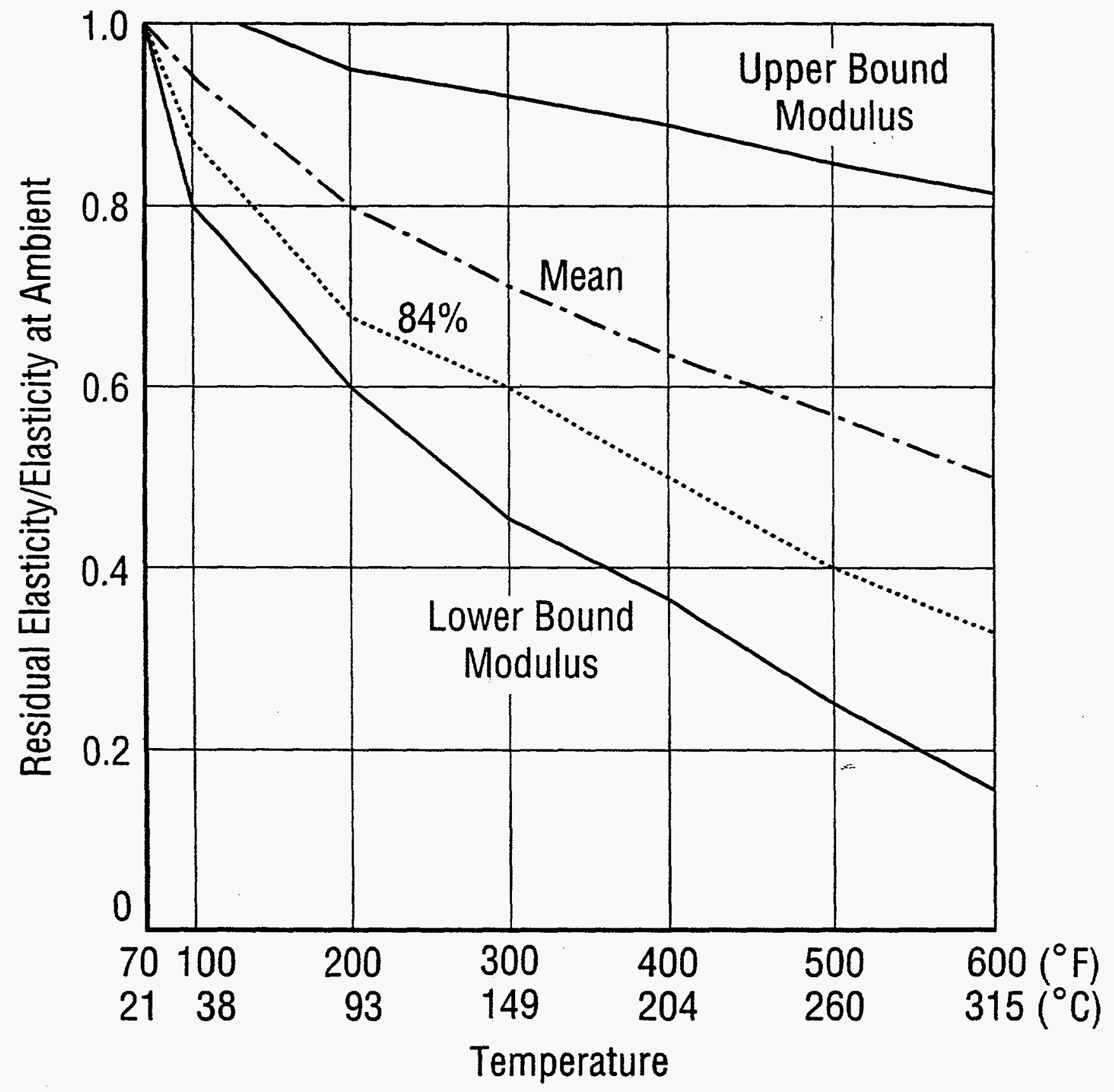

Figure 3 Reduction of the Modulus of Elasticity of Concrete at Elevated Temperatures 
higher strain especially when the moisture path is constrained. Figure 4 a illustrates this point with typical stress-strain diagrams obtained by testing sealed specimens fabricated using Iimestone aggregates and subjected to a temperature rise through the $180^{\circ} \mathrm{C}\left(356^{\circ} \mathrm{F}\right)$ level (Reference 22$)$. The curves reveal a significant and progressive increase in the strain corresponding to the peak stress. At $180^{\circ} \mathrm{C}\left(356^{\circ} \mathrm{F}\right)$, the corresponding strain has increased by about 50\%. However, as shown in Figure $4 \mathrm{~b}$, when similar laboratory specimens were tested in an unsealed environment through the same temperature range, the results revealed practically no influence of the rise in temperature on the ductility of the concrete (Reference 22). This indicates that certain test conditions, specifically the moisture retention capability and evaporation paths, have a strong influence on the characteristics of the stress-strain diagrams. stress-strain curves for lightweight aggregate concrete specimens tested to failure are shown in Figure 5 (References 5 and 30 ).

Stress-strain experimental data applicable to concrete made using other types of aggregates at elevated temperature are scarce. Because of this, lower and upper bound stress-strain diagrams illustrating the influence of elevated temperatures on conventional concrete have been postulated by use of the Iimited existing data and are shown in Figure 6 (Reference 25). Such stress-strain diagrams have been used to assess the load bearing capacity of structural members. At $150^{\circ} \mathrm{C}\left(302^{\circ} \mathrm{F}\right)$, the lower bound data show a reduction in strength of $30 \%$ and an increase in strain at the peak strength of $20 \%$.

\section{6 creep}

Creep is defined as an increase in strain with time under a constant stress. It affects the distribution of stress and deformation in structural members, and may cause undesirable effects although in some situations creep is beneficial because it reduces stress concentrations around holes and defects. Creep in concrete is a function of the evaporable water and reduces to zero when no evaporable water is present. When a concrete test specimen is subjected to a low uniaxial load, it initially deforms elastically and then creeps if the load is sustained. The release of the load results in an elastic strain recovery followed by a creep recovery with time. Typically, the recovered creep strain is smaller than the recovered elastic strain. The mechanism of creep in concrete is believed to be mainly due to the deformation of the cement gel and the diffusion of absorbed moisture. In concrete, the magnitude of creep in compression is the same as that in tension. At room temperature, the primary factors influencing the development of creep in concrete structures are the type of aggregates and the water/cement ratio. For example, concrete made using sandstone aggregates exhibits three (3) times more creep than that made using limestone aggregates as shown in Figure 7 (Reference 28). Also, the creep of concrete under load can easily be increased by $25 \%$ simply by changing the water to cement 


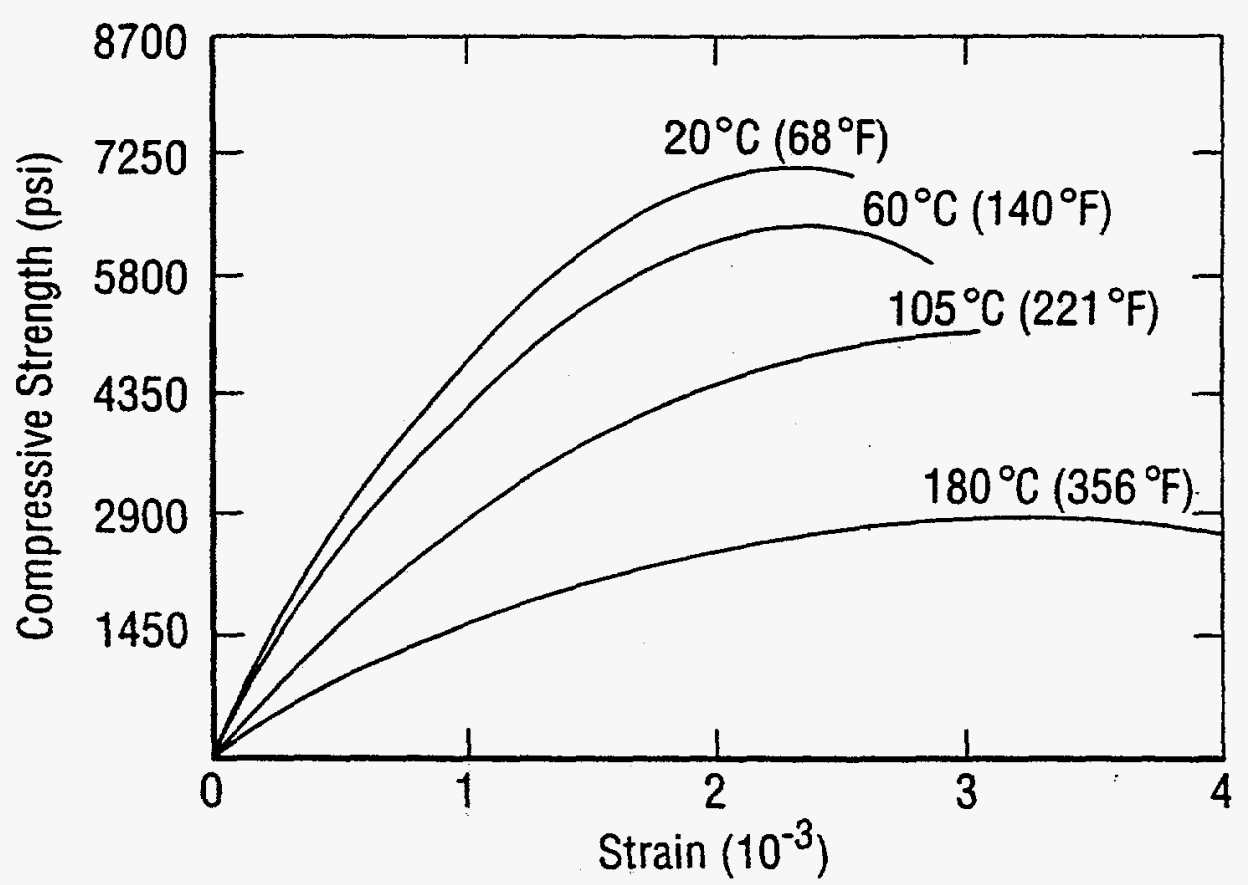

(a) Sealed Specimens

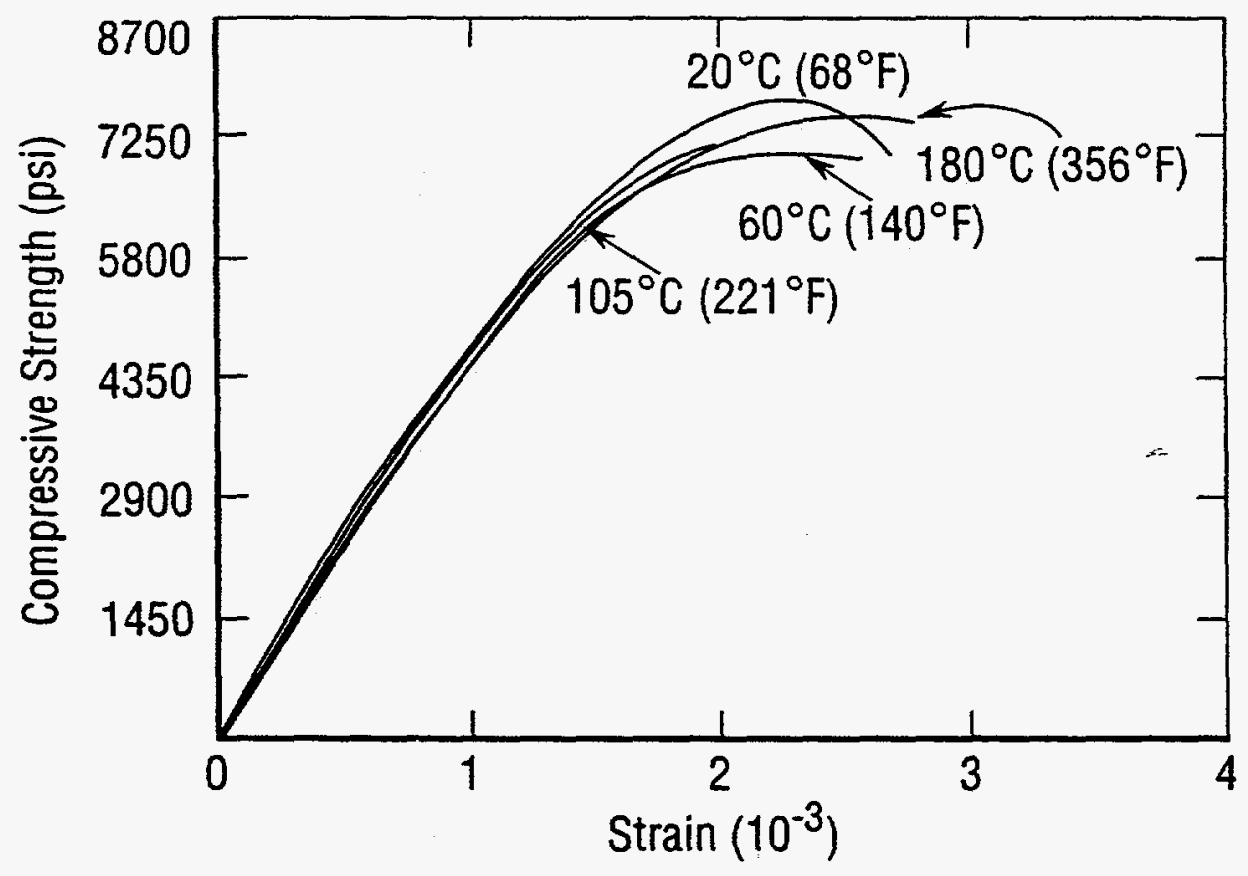

(b) Unsealed Specimens

Figure 4 stress-Strain Diagrams of Iimestone Aggregate Concrete 


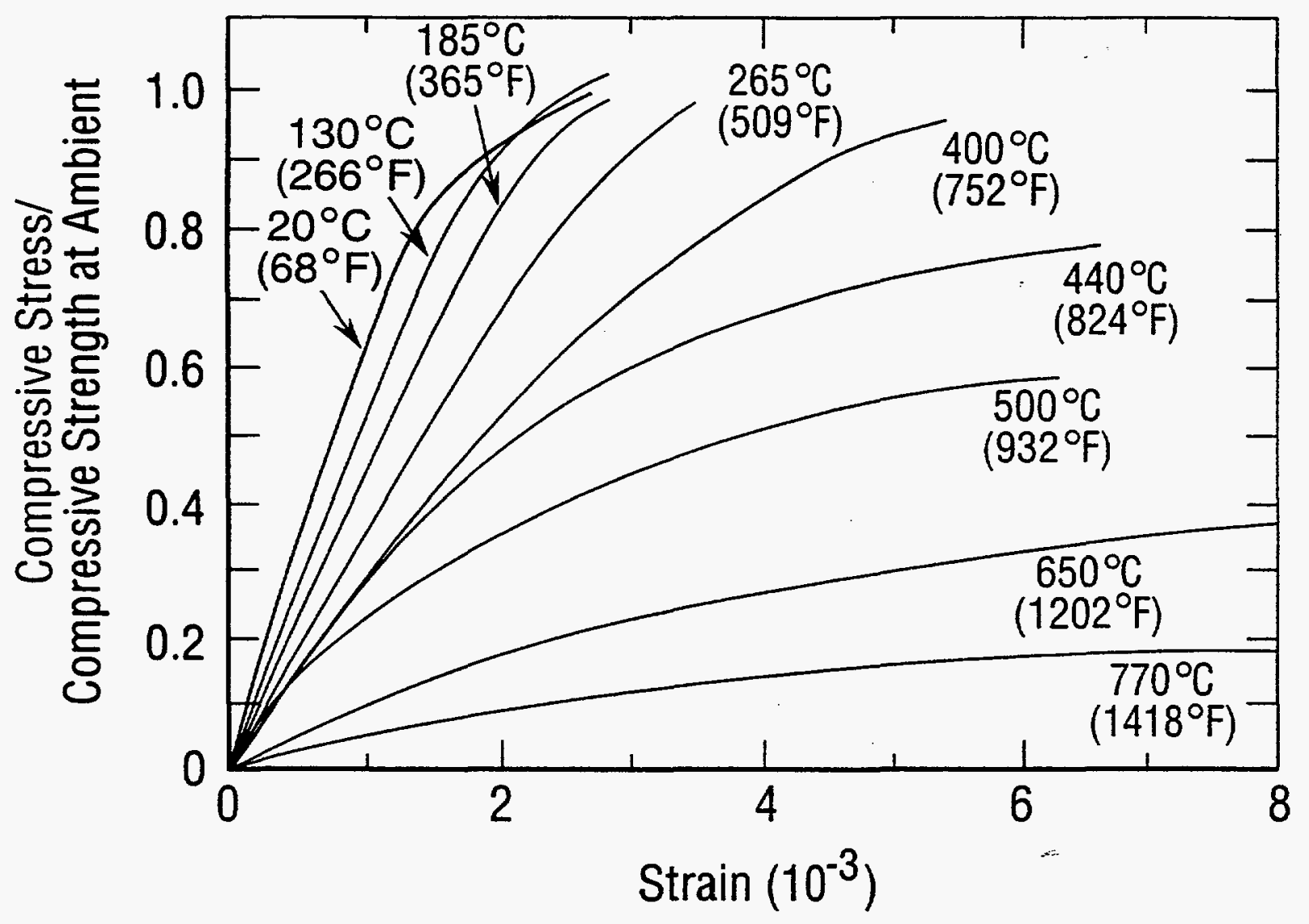

Figure 5 stress-strain Behavior of Lightweight Aggregate Concrete 


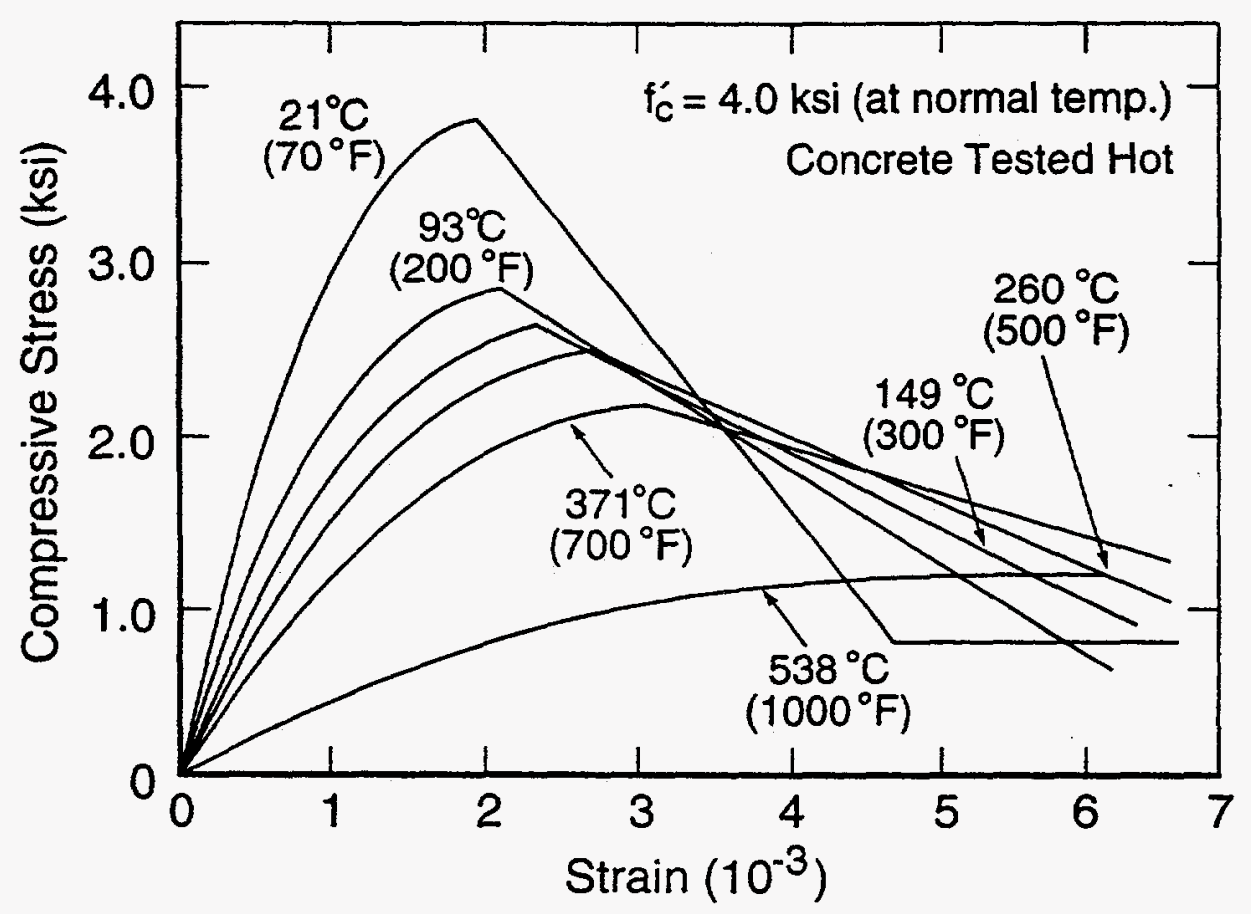

(a) Lower Bound Data

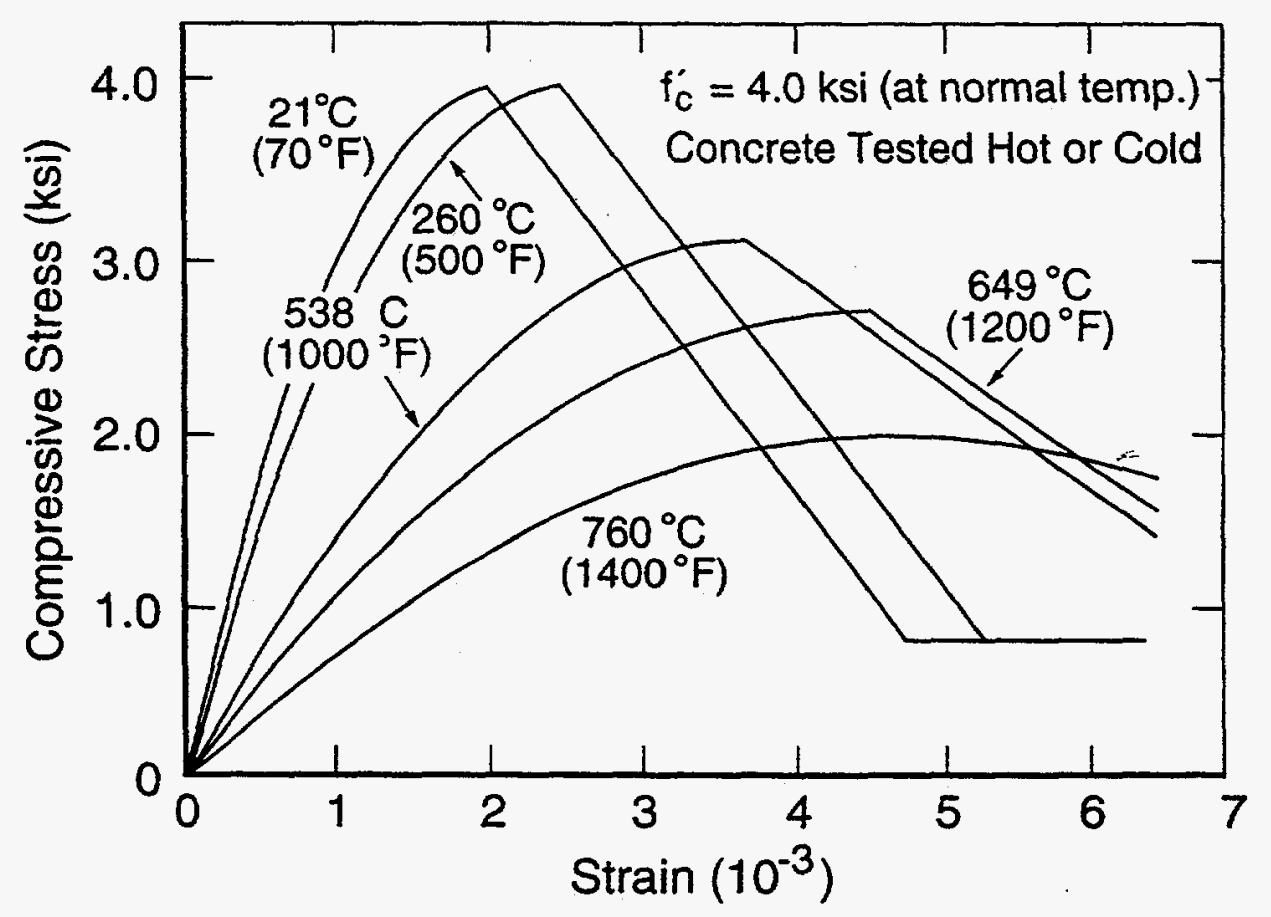

(b) Upper Bound Data

Figure 6 Typical Stress-Strain Diagrams for Modeling Concrete 


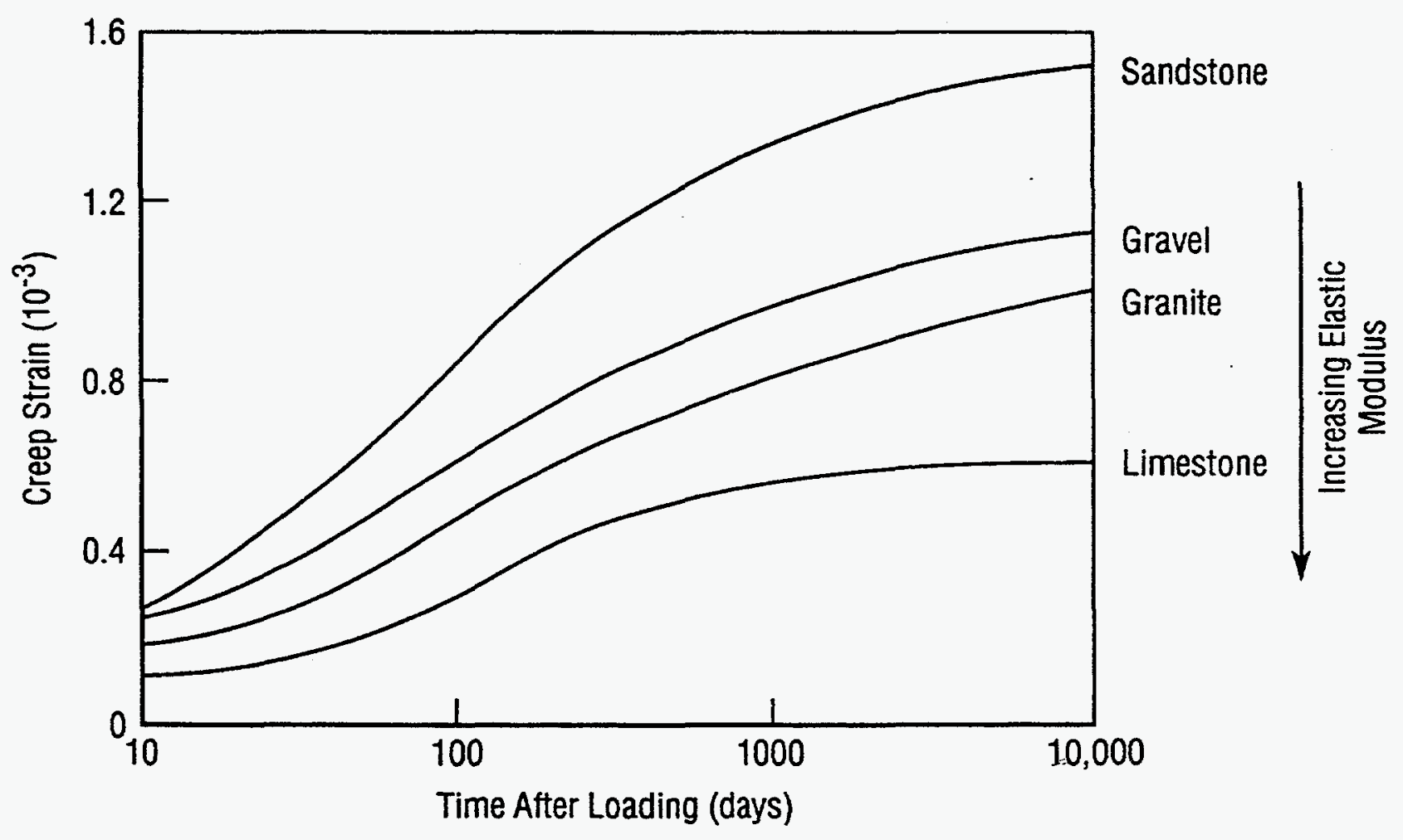

Figure 7 Effect of Aggregate Modulus on Creep of Concrete at Ambient Temperature 
ratio from 0.40 to 0.45 by weight (Reference 7). At room temperature, creep typically varies exponentially with time under a constant load and increases linearly with an increasing applied stress up to a ratio of stress over strength of about 0.5 (Reference 28). Creep also increases with an increasing moisture content. However, it decreases with increasing maturity of concrete. Initially, the creep increases rapidly after loading and, after a few years, the rate of increase becomes insignificant.

Similar to other solids, the creep in concrete increases with temperature. It is caused by the diffusion of solid particles and moisture into the gaps of the material. The time-dependent deformation behavior of concrete when subjected to varying temperatures, moisture contents, curing ages, stress levels, and durations of loading has been studied extensively in the literature (e.9., References $7,15,27,33-43)$. The main purpose of these studies has been to predict the influence of elevated temperatures on the strain behavior, both elastic and creep, of concrete used in the nuclear power industry with particular emphasis on concrete in containment structures. In the following sections, the experimental data is used to quantify the influences of elevated temperatures and other parameters on the creep of concrete. The creep data obtained at temperature levels below and above $121^{\circ} \mathrm{C}$ $\left(250^{\circ} \mathrm{F}\right)$ are considered seperately.

\section{6 .1 Creep at temperatures below $121^{\circ} \mathrm{C}\left(250^{\circ} \mathrm{F}\right)$}

Some of the early test data (1960's vintage) are shown in Figure 8 (Reference 7). For several levels of temperature, Figure 8 shows the variation of the total strain per unit of applied stress with time or age (after loading the specimen). Total strain implies elastic strain and creep strain. These data were obtained for sealed concrete specimens cured in water for three days immediately after casting and thereafter cured at $63^{\circ} \mathrm{F}\left(17^{\circ} \mathrm{C}\right)$ and $90 \%$ relative humidity for ten days prior to exposure to elevated temperatures and testing. The water to cement ratio of the concrete was 0.45 by weight. Initially, the creep increased rapidly as the temperature level was raised from $20^{\circ} \mathrm{C}\left(68^{\circ} \mathrm{F}\right)$ to $94^{\circ} \mathrm{C}$ $\left(201^{\circ} \mathrm{F}\right)$, and thereafter levelled off and gave scattered results. Considering the specific strain (total strain per unit stress) at $20^{\circ} \mathrm{C}\left(68^{\circ} \mathrm{F}\right)$ as reference, the thermal scaling factors for the specific strains at elevated temperatures are given in Table 1. At $94^{\circ} \mathrm{C}\left(201^{\circ} \mathrm{F}\right)$, the specific strain after 100 days is 2.44 times that of its value at ambient temperature. Reference 7 also provides the results of additional creep tests carried out on sealed limestone concrete specimens subjected to uniaxial loads at temperatures ranging from $20^{\circ} \mathrm{C}\left(68^{\circ} \mathrm{F}\right)$ to $93^{\circ} \mathrm{C}\left(200^{\circ} \mathrm{F}\right)$ and for periods of loading varying from 7 to 400 days. The total strain, both elastic and creep, predicted (by linear extrapolation) over a 30-year period is shown in Figure 9. At each stage of the loading the ratio of the total strain at $45^{\circ} \mathrm{C}\left(113^{\circ} \mathrm{F}\right)$ to that at ambient temperature varied 


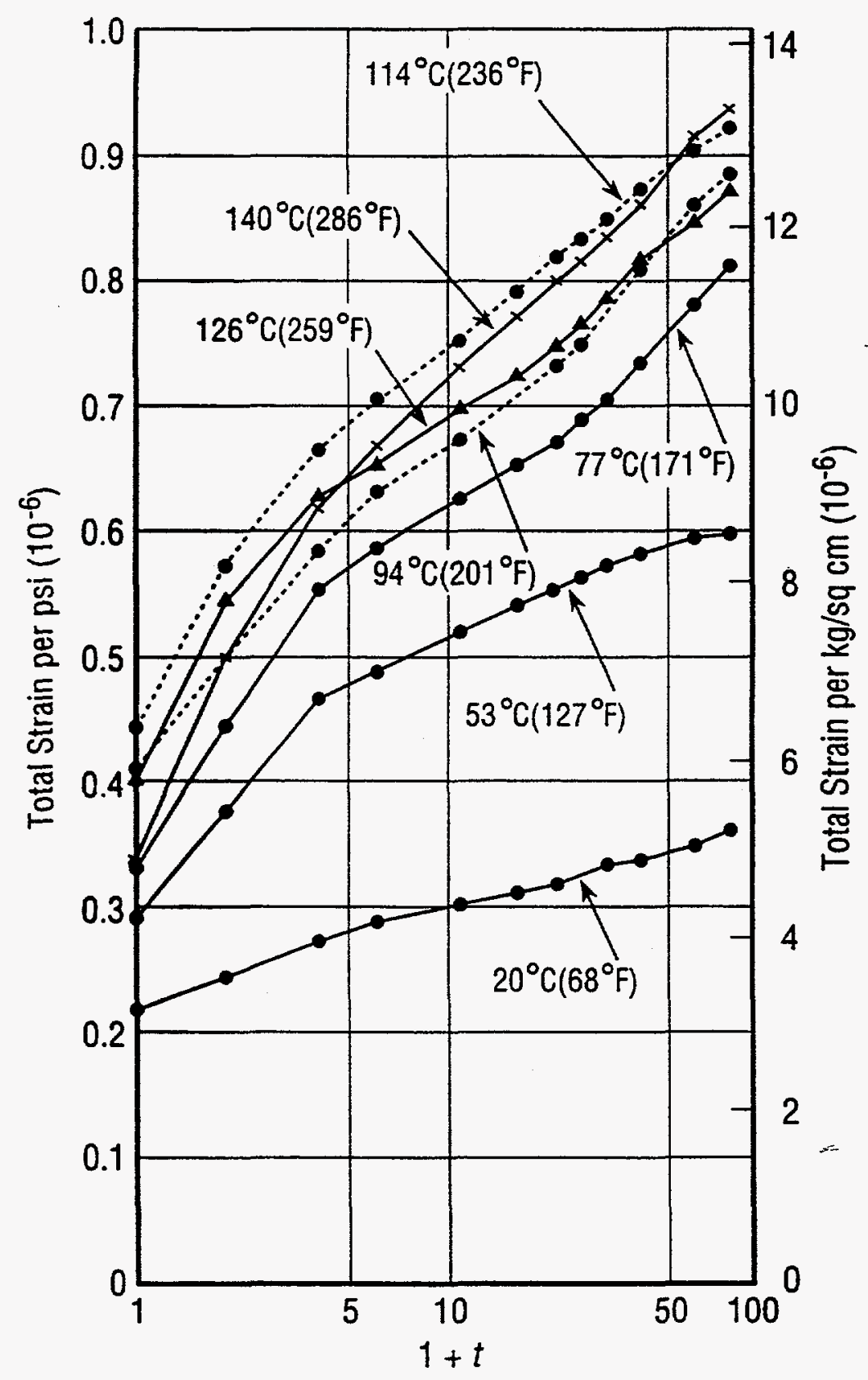

Where $t=$ Time After Load Application In Days

Figure 8 Variation of Total strain with Time at Elevated Temperature 


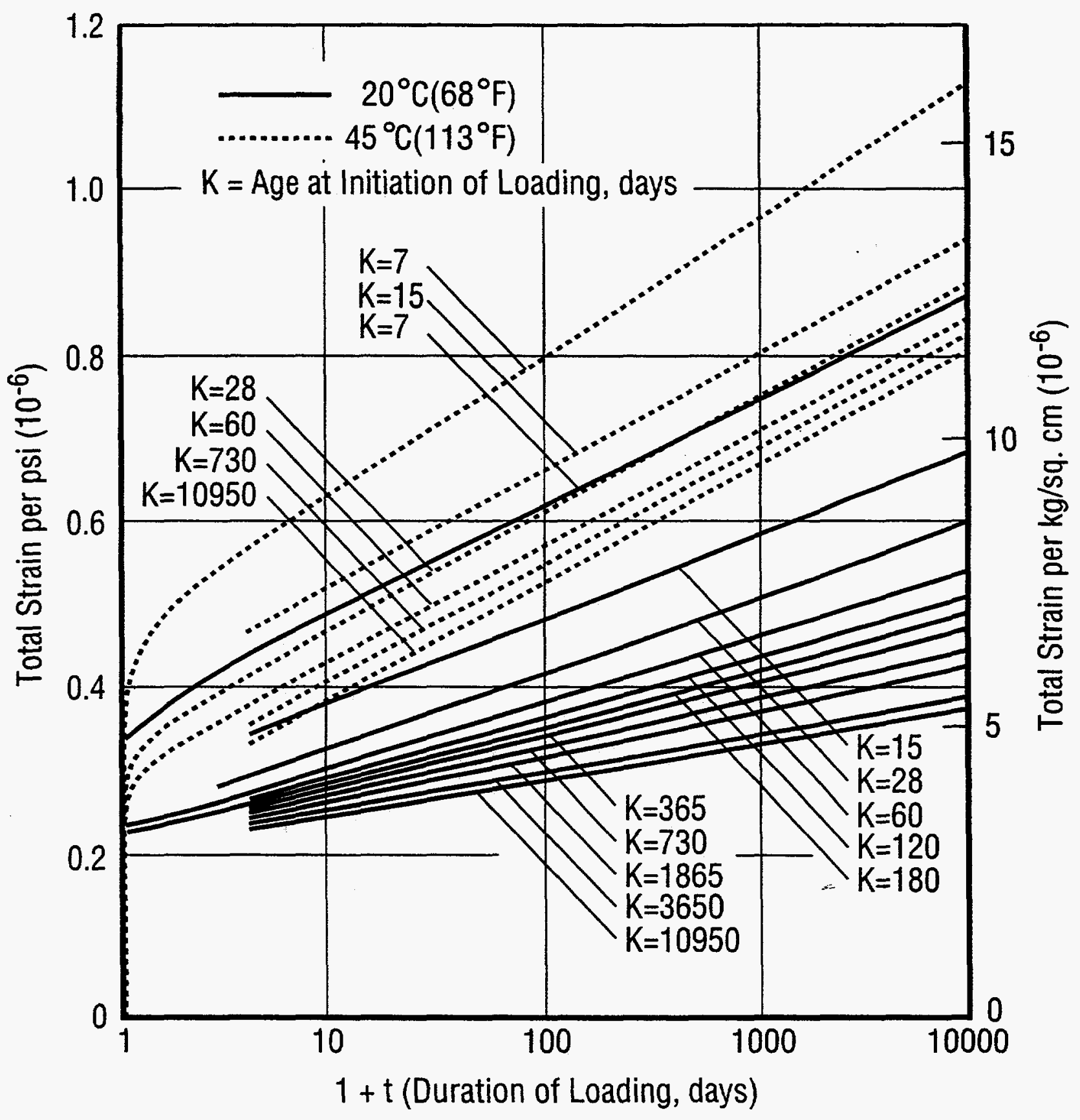

Figure 9 Variation of Total strain with Time at $68^{\circ} \mathrm{F}\left(20^{\circ} \mathrm{C}\right)$ and $113^{\circ} \mathrm{F}\left(45^{\circ} \mathrm{C}\right)$ 
(approximately) between 1.5 and 1.6 . These results are in close agreement with those given in Table 1.

Table 1 - Thermal scaling Factors at Temperatures Below $121^{\circ} \mathrm{C}\left(250^{\circ} \mathrm{F}\right)$

\begin{tabular}{|c|c|c|c|c|}
\hline \multirow{2}{*}{$\begin{array}{c}\text { Time } \\
\text { (days) }\end{array}$} & \multicolumn{5}{|c|}{ Thermal Factors (TF) } \\
\cline { 2 - 5 } & $20^{\circ} \mathrm{C}\left(68^{\circ} \mathrm{F}\right)$ & $53^{\circ} \mathrm{C}\left(127^{\circ} \mathrm{F}\right)$ & $77^{\circ} \mathrm{C}\left(171^{\circ} \mathrm{F}\right)$ & $94^{\circ} \mathrm{C}\left(201^{\circ} \mathrm{F}\right)$ \\
\hline 1 & 1 & 1.33 & 1.56 & 1.86 \\
5 & 1 & 1.70 & 2.04 & 2.16 \\
10 & 1 & 1.73 & 2.08 & 2.23 \\
50 & 1 & 1.72 & 2.24 & 2.47 \\
100 & 1 & 1.64 & 2.30 & 2.44 \\
\hline
\end{tabular}

Reference 37 describes a test program to determine the strain behavior, elastic and creep, of concrete specimens subjected to uniaxial and multiaxial compressive stress combinations at temperatures varying between $27^{\circ} \mathrm{C}\left(81^{\circ} \mathrm{F}\right)$ and $95^{\circ} \mathrm{C}\left(203^{\circ} \mathrm{F}\right)$ for periods of loading up to two years. The concrete was manufactured from sulfate resisting cement and limestone aggregates $3 / 8$ in. $(0.95 \mathrm{~cm})$ maximum size. Two moisture conditions were used in the test program, namely, sealed specimens and air-dried specimens at $46 \%$ relative humidity. The variations of the data for the creep strain per unit applied stress with time after the load application are shown in Figures $10 \mathrm{a}$ and $10 \mathrm{~b}$. It is clear that the magnitude of the creep strain increases with temperature, the creep strain at $95^{\circ} \mathrm{C}\left(203^{\circ} \mathrm{F}\right)$ is about 3 to 4 times that at $27^{\circ} \mathrm{C}\left(81^{\circ} \mathrm{F}\right)$ and this thermal scaling factor remains practically constant throughout the duration of loading. Reference 37 also reports that the creep of the air-dried specimens was virtually completed after 20 days of loading for all ranges of temperatures considered. with the result that, after 200 days of loading, the creep of the wet sealed specimens tested at $73^{\circ} \mathrm{C}\left(163^{\circ} \mathrm{F}\right)$ exceeded that of the dried specimens by about 10 times. This indicates the need to know the moisture condition of the concrete at all ages before accurate predictions can be made of the creep strain due to elevated temperatures. Moreover, the creep strain under multiaxial stress was found to be lower than that at uniaxial load, and the reduction is approximately proportional to the magnitudes of the applied radial stress. An approximate formula for predicting the creep strain under a multiaxial stress field, $C_{m}$, from the creep strain under uniaxial stress, $C_{x}$, is as follows (Reference 37):

$$
C_{m}=C_{x}\left[1-v\left(\sigma_{y}+\sigma_{z}\right) / \sigma_{x}\right]
$$


(a)

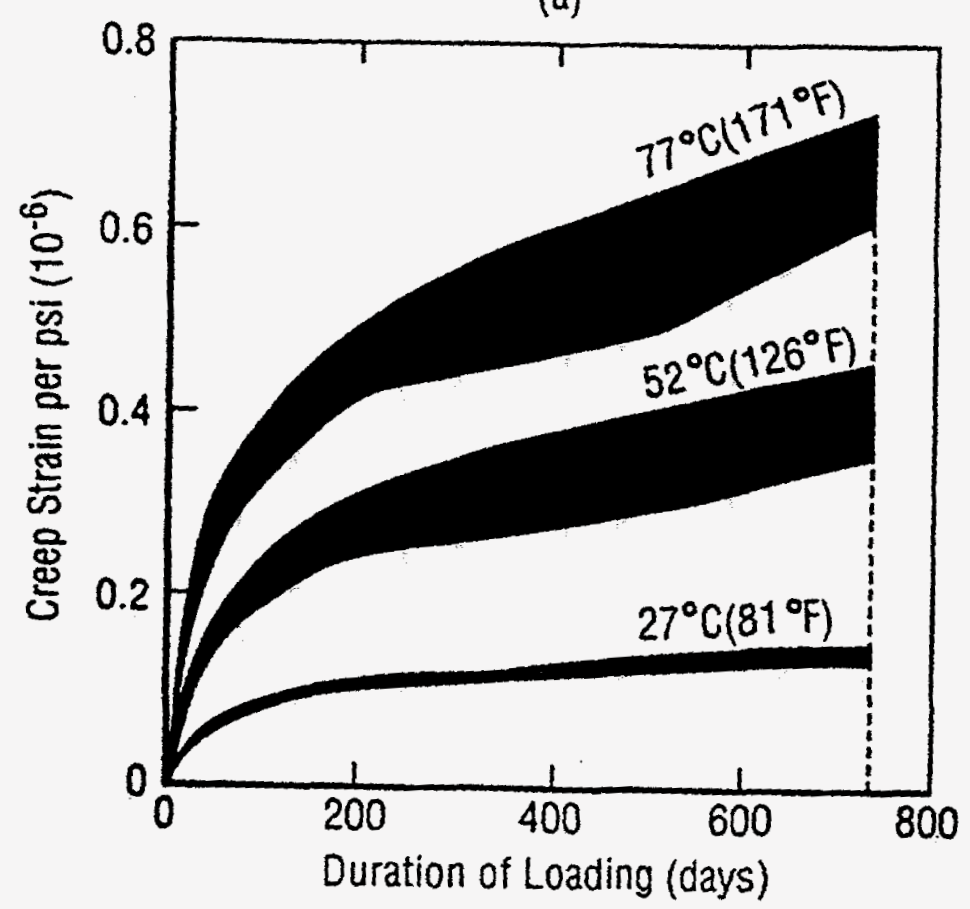

(b)

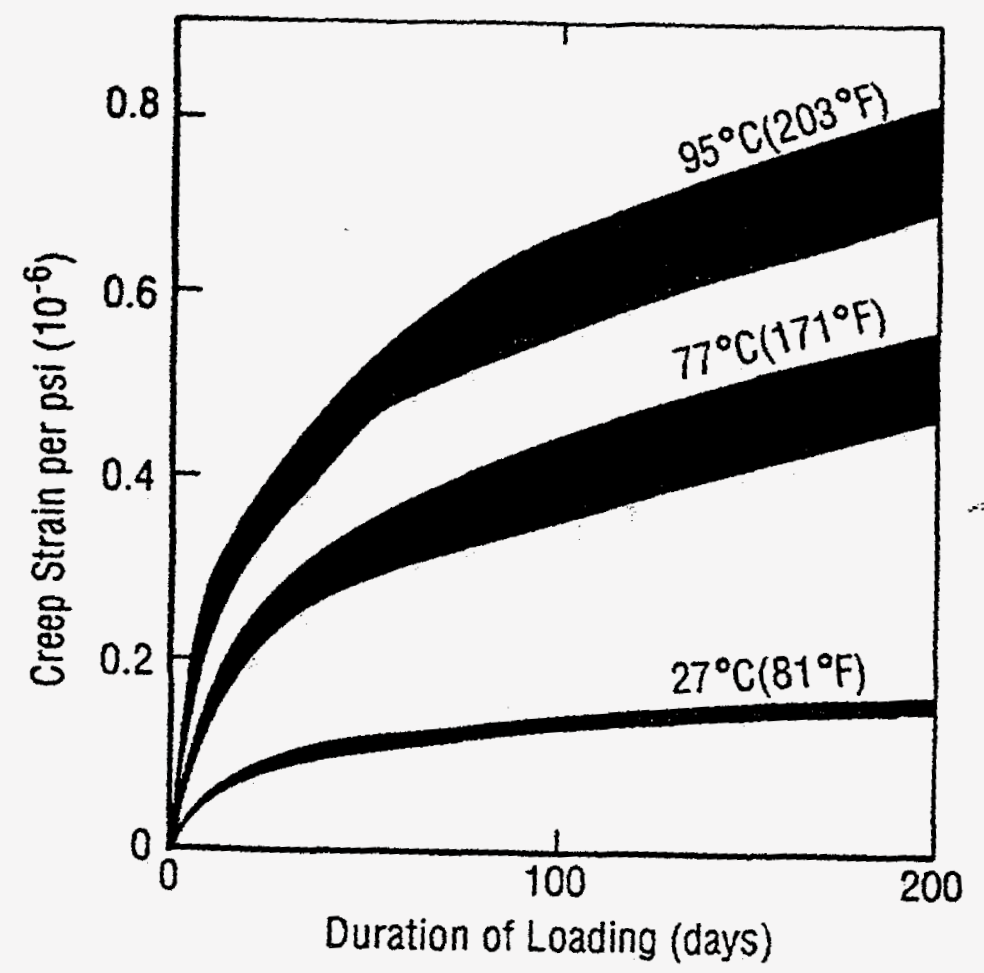

Figure 10 Variation of Creep Strain Per Unit Applied Stress with rime 
where $\sigma_{x}$ designates the axial stress, $\sigma_{y}$ and $\sigma_{z}$ are the stresses at right angles, and $v$ is Poisson's ratio.

The creep behavior of concrete in the presence of temperature, moisture, different aggregates, and loading conditions similar to those encountered in prestressed concrete reactor vessel structures has been investigated in Reference 42. In particular, the investigation emphasized finding the influence of varying the modulus of elasticity of the aggregate; curing history prior to loading; temperature level; and state of stress during loading. Two levels of temperature, $23^{\circ} \mathrm{C}$ and $66^{\circ} \mathrm{C}\left(73^{\circ} \mathrm{F}\right.$ and $\left.150^{\circ} \mathrm{F}\right)$, and four types of loading, uniaxial, biaxial, hydrostatic and triaxial states of stress with both axial stress and radial confining stress ranging from 0 to $17 \mathrm{MPa}$ ( 0 to $2400 \mathrm{psi}$ ) were investigated. The test specimens were manufactured from Type II Portland cement and three different aggregates; chert, limestone and graywacke. The crushed limestone aggregate, $19 \mathrm{~mm}$ ( $3 / 4 \mathrm{in.)}$ maximum size, was used to simulate a typical concrete mixture while the other mixtures containing crushed graywacke and chert gravel, aggregates with elastic moduli lower and higher, respectively, than that of the limestone concrete were used to explore the influence of aggregates on the creep behavior of concrete. The curing history included specimens which were sealed shortly after casting and remained so throughout the test to prevent evaporation losses, and air-dried specimens. The air-dried specimens were allowed (after 7 days curing) to dry in air at $23^{\circ} \mathrm{C}\left(73^{\circ} \mathrm{F}\right)$ and $50 \%$ relative humidity for the remainder of the $90-$ day period preceding testing. The saturated sealed specimens represent the interior of mass concrete while the air-dried specimens, which exhibited considerable moisture losses, are representative of concrete near the exterior surface. The following are the main conclusions of this particular investigation concerning the influence of elevated temperature on the creep of concrete (Reference 42):

- Creep strains at $66^{\circ} \mathrm{C}\left(150^{\circ} \mathrm{F}\right)$ were found to be 1.79 and 1.51 times that at $23^{\circ} \mathrm{C}\left(73^{\circ} \mathrm{F}\right)$ for the compressive and tensile creep, respectively.

- Creep under multiaxial stress was less than that associated with uniaxial creep. This applies to both the tensile and compressive creeps. The values of the compressive creep for the limestone concrete differed by a factor of 1.00 (uniaxial loading); 0.45 (hydrostatic); 0.69 (biaxial); and, 0.84 (triaxial).

- Compressive and tensile creep strains are generally proportional to the inverse of the elastic moduli of both aggregate and concrete. In particular, the higher the modulus of elasticity of the aggregates the greater the restraint offered by the aggregate portion of the specimen to the potential overall creep of the concrete. This behavior is also observed at ambient temperatures as indicated in Figure 7 . 
- The creep Poisson's ratio is generally slightly less than the elastic Poisson's ratio. It also tends to decrease with a rise in temperature.

Additional results of creep tests made on sealed concrete specimens under various combinations of temperature, stress level and age at loading were reported in Reference 33. The test conditions included temperatures of 23,43 and $71^{\circ} \mathrm{C}(73,110$ and $160^{\circ} \mathrm{F}$ ); curing ages before loading of 28,90 and 270 days; and stress levels of 30,45 and 60 percent of the compressive strength. The creep loads were maintained for one year, with creep recovery observed on selected groups of specimens for a period of 90 days after the loading was removed. The concrete materials were Type II cement (low alkali), natural quartz sand and crushed dolomitic limestone with water to cement ratios varying between 0.381 and 0.384 . The 60-day compressive strength of the concrete specimens varied from 51 to $53 \mathrm{MPa}(7400$ to $7700 \mathrm{psi})$. The variations of the total strain per unit of applied stress with time under load are shown in Figure 11 for the three temperature levels considered in the test program. It is reported in Reference 33 that at $71^{\circ} \mathrm{C}$ $\left(160^{\circ} \mathrm{F}\right)$, the strains per unit of applied stress of all the specimens tested are about 1.6 to 2.3 times the corresponding values at $23^{\circ} \mathrm{C}\left(73^{\circ} \mathrm{F}\right)$. Similarly, Figure 11 shows that the ratio of the strains at $43^{\circ} \mathrm{C}\left(110^{\circ} \mathrm{F}\right)$ to those at $23^{\circ} \mathrm{C}\left(73^{\circ} \mathrm{F}\right)$ vary from 1.15 to 1.3 .

\section{6 .2 Creep at temperatures above $121^{\circ} \mathrm{C}\left(250^{\circ} \mathrm{F}\right)$}

Creep measurements at temperatures higher than $121^{\circ} \mathrm{C}\left(250^{\circ} \mathrm{F}\right)$ are provided in References 15,38 and 41 . Reference 15 reports results of creep data on standard and special (heat-resistant) concrete specimens at ambient and three elevated temperature levels, namely, 150,300 and $450^{\circ} \mathrm{C}\left(302,572\right.$ and $\left.842^{\circ} \mathrm{F}\right)$. The time variation of the creep strain per unit applied stress of the standard concrete sample (ordinary portland cement, limestone aggregate, water to cement ratio of 0.4) is shown in Figure 12 for 150 and $300^{\circ} \mathrm{C}\left(302\right.$ and $\left.572^{\circ} \mathrm{F}\right)$ temperatures. The specimens were cured for one month in water at $23^{\circ} \mathrm{C}\left(73^{\circ} \mathrm{F}\right)$ followed by one month in air at the same temperature and then tested. Because of the air-dried moisture condition of the specimens, these creep strains are smaller than those for sealed specimens at lower temperature levels. The results of the creep measurements carried out in the test program of Reference 15 indicate that the ratio of the unit creep rates at $150^{\circ} \mathrm{C}\left(302^{\circ} \mathrm{F}\right)$ and ambient temperature is 1.6 while the corresponding ratio at $300^{\circ} \mathrm{C}\left(572^{\circ} \mathrm{F}\right)$ and ambient temperature is 2.27 .

Additional data on the creep behavior of concrete at high temperatures are reported in Reference 41. In particular, it presents creep strains based on experimental data involving sealed cylindrical specimens fabricated from conventional concrete with a specified strength of about $6000 \mathrm{psi}$. The specimens were loaded by three stress ratios, $\sigma / f^{\prime} c$ of $0.2,0.4$ and 0.66 , and heated to 


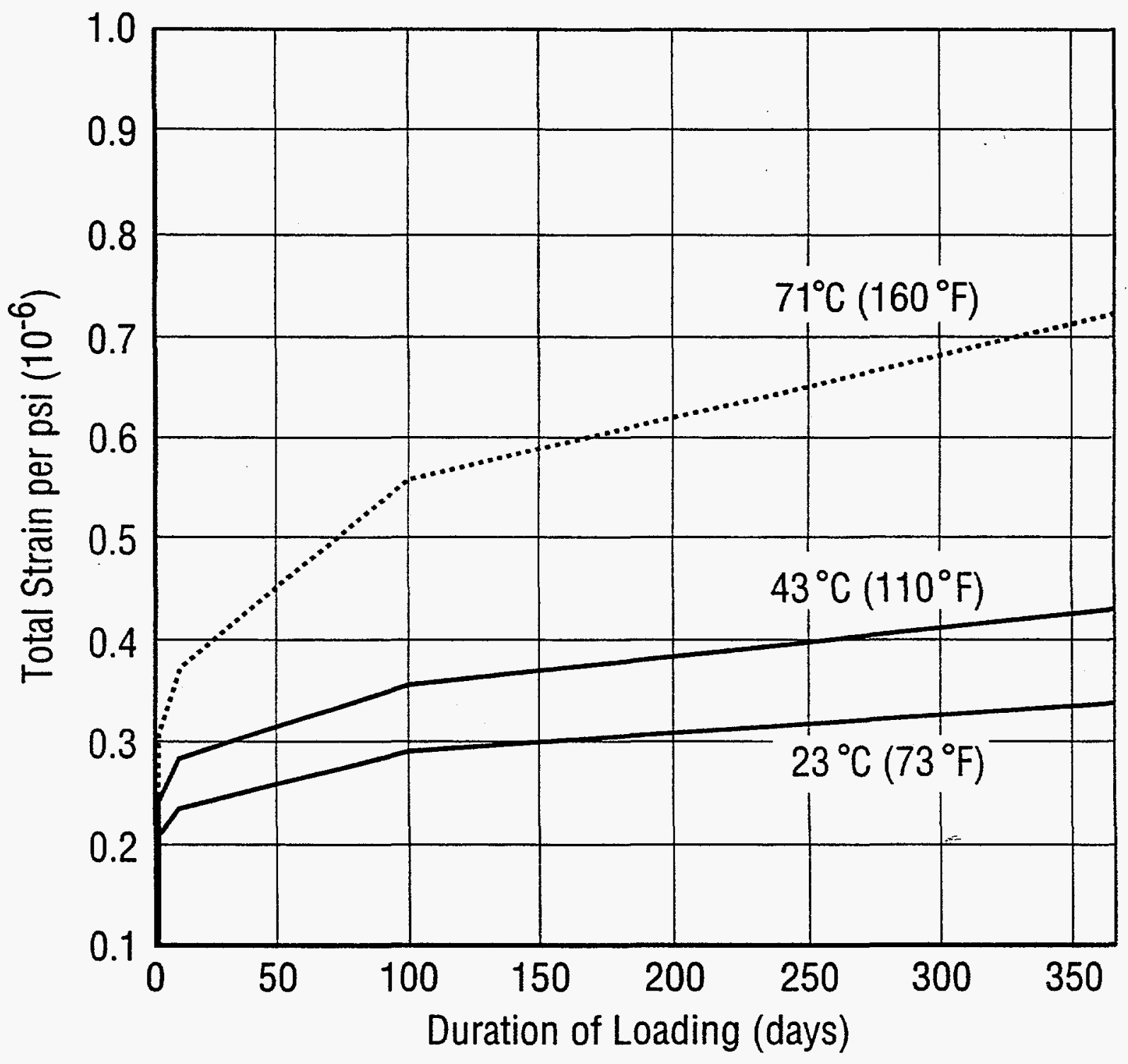

Figure 11 Variation of Total Strain Per Unit Applied Stress with Time 


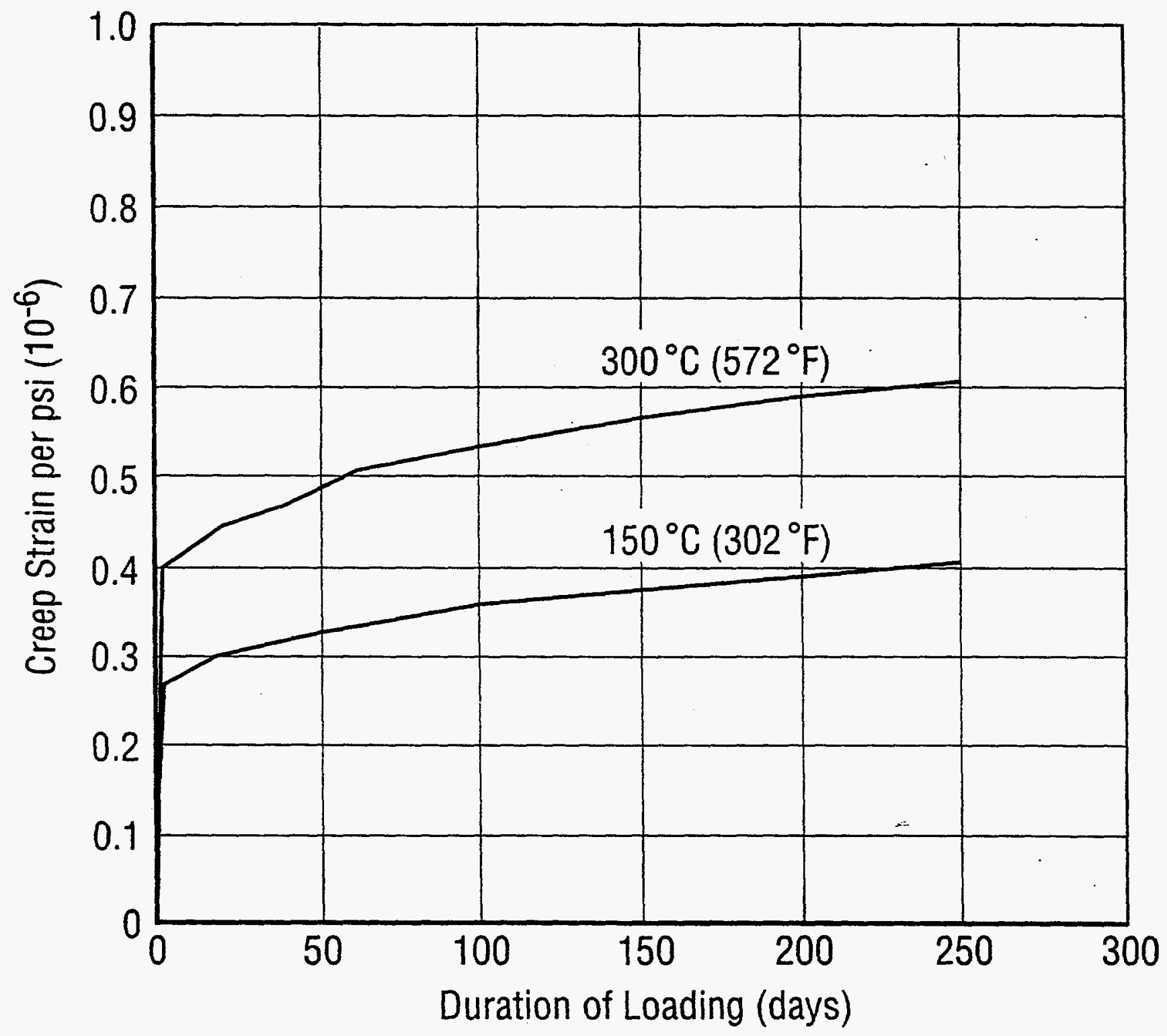

Figure 12 Variation of Creep strain Per Unit Applied Load with Time 
various temperatures ranging from 20 to $400^{\circ} \mathrm{C}$ ( 68 to $752^{\circ} \mathrm{F}$ ) for seven days. The dependence of the unit creep strains on temperature is shown in Figure 13. These strains are larger than the strains experienced by air dried specimens at the same temperature levels (compare the results with those in Figure 12). Considering the creep strain at ambient temperature, i.e., $20^{\circ} \mathrm{C}$ $\left(68^{\circ} \mathrm{F}\right)$, as reference, the thermal scaling factors for the creep strains at elevated temperatures after 7 days of loading are given in Table 2. (These factors are the average values for the three stress ratios mentioned previously.)

Table 2 - Thermal Scaling Factors at Elevated Temperatures After 7 Days of Loading

\begin{tabular}{|lr|c|}
\hline \multicolumn{2}{|c|}{ Temperature } & $\begin{array}{c}\text { Thermal Factor } \\
\text { (TF) }\end{array}$ \\
\hline $40^{\circ} \mathrm{C}$ & $\left(104^{\circ} \mathrm{F}\right)$ & 1.37 \\
$60^{\circ} \mathrm{C}$ & $\left(140^{\circ} \mathrm{F}\right)$ & 1.55 \\
$80^{\circ} \mathrm{C}$ & $\left(176^{\circ} \mathrm{F}\right)$ & 1.57 \\
$110^{\circ} \mathrm{C}$ & $\left(230^{\circ} \mathrm{F}\right)$ & 1.50 \\
$125^{\circ} \mathrm{C}$ & $\left(257^{\circ} \mathrm{F}\right)$ & 1.59 \\
$200^{\circ} \mathrm{C}$ & $\left(392^{\circ} \mathrm{F}\right)$ & 2.24 \\
$250^{\circ} \mathrm{C}$ & $\left(482^{\circ} \mathrm{F}\right)$ & 2.71 \\
$300^{\circ} \mathrm{C}$ & $\left(572^{\circ} \mathrm{F}\right)$ & 3.06 \\
$350^{\circ} \mathrm{C}$ & $\left(662^{\circ} \mathrm{F}\right)$ & 4.19 \\
\hline
\end{tabular}

The creep data in Reference 41 were also used to develop a mathematical relation to predict the long-term creep strain in concrete structures subjected to elevated temperature.

The deformation behavior of unsealed concrete specimens subject to elevated temperatures has been studied in connection with fire research. The experimental data indicate that the total strain of a heated concrete specimen under constant load can be predicted by the following formula:

$$
\epsilon_{\text {totaI }}=\epsilon_{t h}(T)+\frac{\sigma}{E(T)}[I+\phi(\sigma, T)]
$$

where $\epsilon_{t h}(T)$ stands for the thermal expansion strain, $\sigma$ is the applied stress, $E(T)$ the modulus of elasticity, and $\phi(\sigma, T)$ is the non-steady-state creep function (Reference 27). Figure 14 shows the variation of the $\phi$-function for different types of concrete. A substantial increase in the deformation occurs when the temperature is raised above $400^{\circ} \mathrm{C}\left(752^{\circ} \mathrm{F}\right)$. 


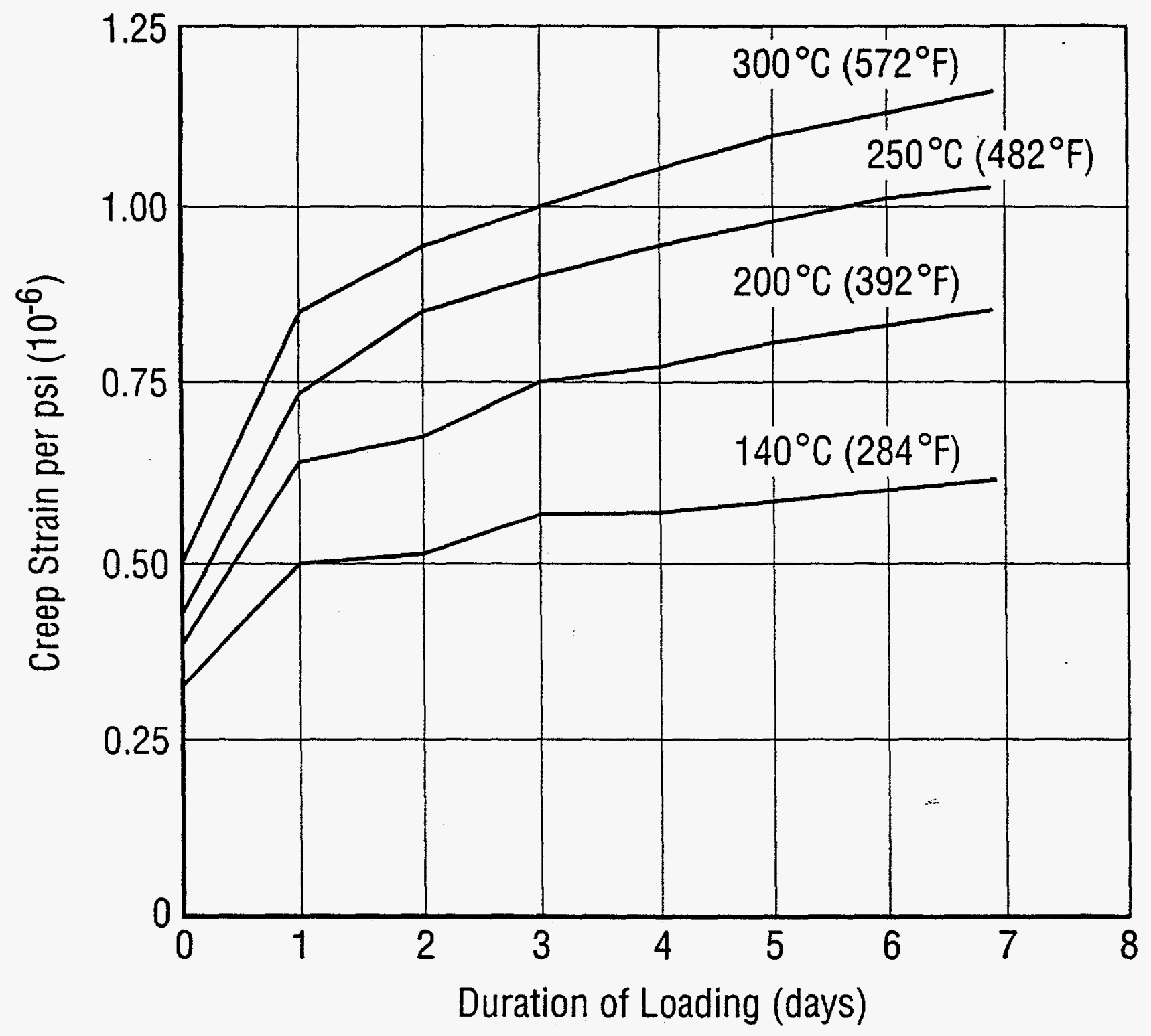

Figure 13 Variation of Creep Strain Per Unit Applied Load with Time 


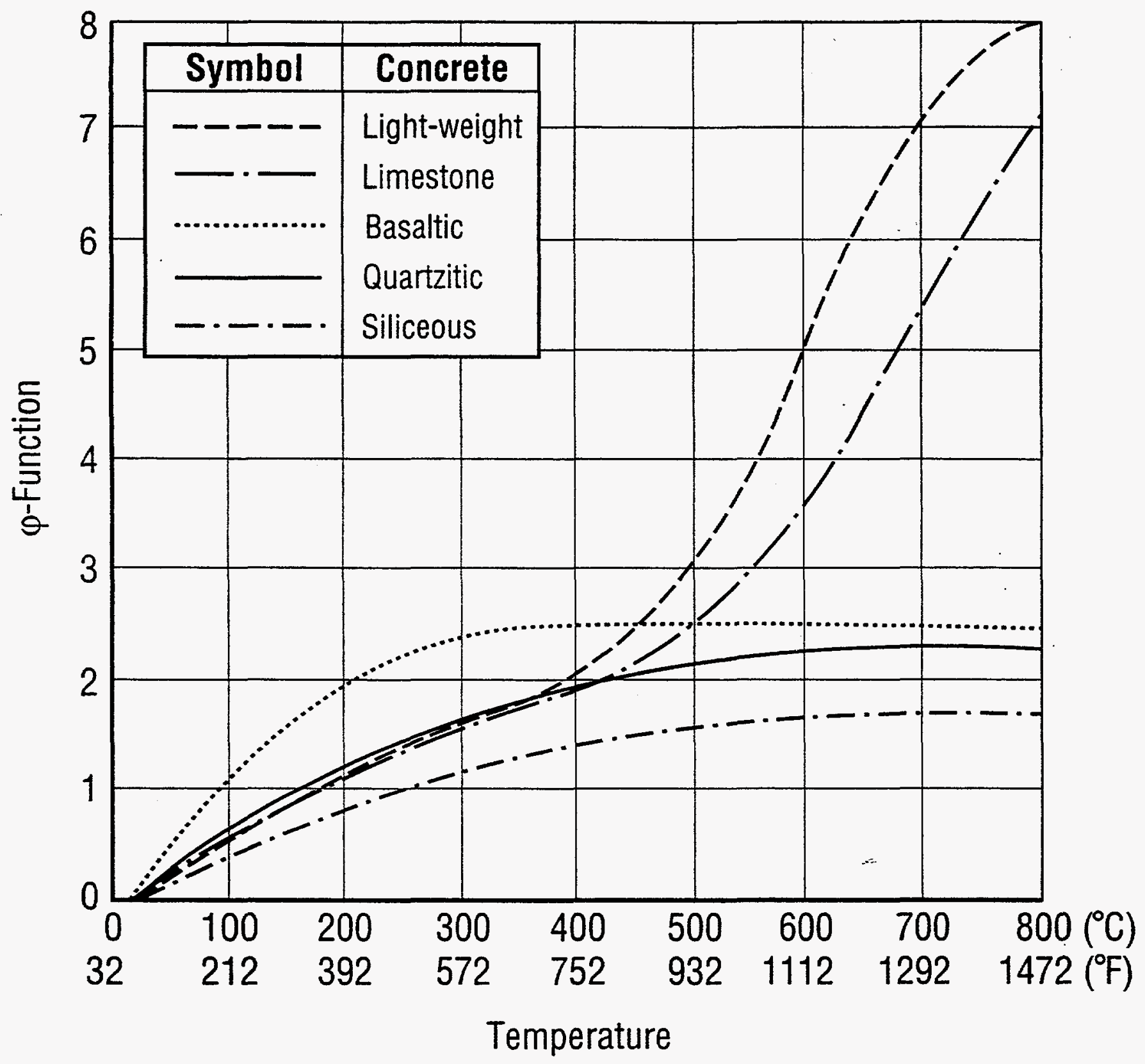

Figure 14 Creep Function of Different Concretes Appearing in Equation (2) 


\subsubsection{Thermal scaling factor}

In applying the foregoing creep data to the concrete vaults of the waste storage tanks, it is observed that the effect of elevated temperature on the creep strain can be accounted for by multiplying the creep strain at ambient temperature by a temperature factor, $T F$, which is a linearly increasing function of the temperature. Moreover, the concrete vaults are relatively massive structures with a significant volume of reinforcing steel. creep of the concrete will transfer a portion of the load that was originally carried by the concrete to the reinforcing steel. The vaults are subjected to a multiaxial state of stress and the concrete in most tanks have aged considerably before being exposed to elevated temperatures. Thus, the actual creep in the vaults is expected to be less than the uniaxial creep in test specimens. Using the test data discussed above, the effect of elevated temperature on creep deformation can be conservatively accounted for by multiplying the predicted creep at ambient temperature by a temperature factor, TF, given by

$$
T F=1+0.4\left(\frac{T}{70}\right), 100^{\circ} \mathrm{F} \leq T \leq 600^{\circ} \mathrm{F}
$$

where $\mathrm{T}$ is the concrete temperature in ${ }^{\circ} \mathrm{F}$. The creep at ambient temperature may be predicted by using the approach adopted by ACI Committee 209 (References 44 and 45). In this approach, the ultimate creep coefficient, which is the ratio of creep strain to initial strain, is computed from the relation:

$$
C_{u I t}=\left(1+10 t^{-0.6}\right)\left(e_{c t} / e_{e}\right)
$$

where $t$ is the $t$ ime under load in days, $\epsilon_{c r}$ is the creep strain at time $t$ and $\epsilon_{e}$ is the initial instantaneous (usually considered elastic) strain. When the concrete is drying under load at $40 \%$ relative humidity, the value of $c_{u l t}$ varies between 1.30 and 4.15 and the ACI recommends an average value of 2.35. Correction factors are available to adjust $c_{u l t}$ for different conditions (References 44 and 45 ).

\subsection{Shrinkage}

Shrinkage in concrete occurs because of drying and autogenous volume change. Several factors influence the amount of shrinkage including the type of aggregates, richness of mixture, consistency, etc. Shrinkage strain in massive concrete members is lower than that in smaller members where moisture loss to the external environment is more severe. High shrinkage occurs when the bulk of the capillary-held water in the concrete mix is lost. At ambient temperature, laboratory measurements on sealed concrete specimens 
yielded shrinkage of 65 microstrains after 5 years (Reference 7). The magnitude of shrinkage generally increases with a temperature rise and the process is usually completed when the temperature reaches the level of about $105^{\circ} \mathrm{C}\left(221^{\circ} \mathrm{F}\right)$. For the temperature range of interest in this study, the rise in temperature does not increase the shrinkage in concrete by significant amounts as compared to room temperature. Therefore, for the high-level waste storage tanks, the shrinkage does not play a major role in assessing the structural behavior at elevated temperatures.

\section{8 coefficient of Thermal Expansion}

The mean coefficient of thermal expansion, $\alpha$, represents the change in length per unit length per degree of temperature change in going from ambient to the indicated temperature. A relatively lower value of $\alpha$ means lower induced thermal stress and strain. In concrete, the magnitude of the coefficient is influenced by the type of aggregates and moisture condition. A gravel concrete can have twice the thermal expansion coefficient of limestone concrete (Reference 7). This could be of some consequence since the use of an aggregate with low thermal expansion significantly reduces the thermal stress in concrete due. to elevated temperature. The coefficient of thermal expansion of concrete during the first cycle of heating is typically greater than for the cooling and subsequent thermal cycling, possibly due to the restraining compressive stresses after the first cycle of heating. Also, it should be noted that some aggregates (e.g., limestone) are anisotropic and possess different thermal expansion coefficients in different directions (Reference 15). For typical concrete materials, the coefficient varies in the range of $2.2 \times 10^{-6}$ to $3.9 \times 10^{-6} /{ }^{\circ} \mathrm{C}$ (i.e., $4.0 \times 10^{-6}$ to $7.0 \times 10^{-6} /{ }^{\circ} \mathrm{F}$ ) with an average value of $3.1 \times 10^{-6} /{ }^{\circ} \mathrm{C}$ (i.e., $5.6 \times 10^{-6} /{ }^{\circ} \mathrm{F}$ ) at room temperature (Reference 22). The coefficient of thermal expansion remains approximately constant through a temperature rise to $300^{\circ} \mathrm{C}\left(572^{\circ} \mathrm{F}\right)$ and then increases with further elevation of temperature (Reference 28).

\subsection{Thermal conductivity}

Thermal conductivity is the ability of the material to conduct heat. It is measured by the rate of heat flux per temperature gradient. In concrete, the thermal conductivity, $k$, depends on its composition (type of aggregates, hardened cement paste and void content) and degree of saturation. Generally speaking, quartzitic aggregates give the highest thermal conductivity, limestones and granites give medium values, and basalts possess the lowest values (Reference 7). Concrete with high thermal conductivity is desirable because it permits rapid dissipation of the heat flux so that the thermal gradients through the thickness are minimized resulting in lower thermal stresses. A rise in temperature usually increases the thermal conductivity of the hardened cement and decreases that of the aggregate; the net effect on the thermal conductivity of the concrete is small. For concrete with specific weights varying between 150 to $160 \mathrm{Ibs} / \mathrm{ft}^{3}$, typical values of the 
conductivity coefficient applicable to the waste storage tanks are in the range of 0.75 to $2.13 \mathrm{Btu} / \mathrm{ft}-\mathrm{hr}-{ }^{\circ} \mathrm{F}(13 \mathrm{E}-09$ to $37 \mathrm{E}-09 \mathrm{MW} / \mathrm{cm}-$ $\left.{ }^{\circ} \mathrm{C}\right)$ (Reference 30 ). For a temperature range from ambient to $315^{\circ}$ $\left(600^{\circ} \mathrm{F}\right)$, the influence of temperature on the thermal conductivity of concrete is insignificant and can be neglected (Reference 8).

\subsection{Thermal Diffusivity}

The thermal diffusivity, $h$, measures the rate at which temperature changes take place within a material. Concrete aggregates with increasing values of diffusivity include basalt and limestone. Typical thermal diffusivity values for conventional concrete at room temperature vary between 0.002 to $0.007 \mathrm{~m}^{2} / \mathrm{hr}$ $\left(0.02\right.$ to $\left.0.07 \mathrm{ft}^{2} / \mathrm{hr}\right)$ while at $300^{\circ} \mathrm{C}\left(572^{\circ} \mathrm{F}\right)$ they vary between 0.001 to $0.002 \mathrm{~m}^{2} / \mathrm{hr}\left(0.01\right.$ to $0.02 \mathrm{ft}^{2} / \mathrm{hr}$ ) (References 27 and 30 ). For the waste storage tanks, the rise in temperature has an insignificant influence on the diffusivity.

\subsection{Specific Heat}

The specific heat, $c$, is a measure of the heat capacity of a material and is related to the thermal conductivity, $k$, and thermal diffusivity, $h$, by the expression, $k=$ hco where $\rho$ represents the mass density of the material. Experimental data indicate that the values of the specific heat of concrete increase slightly with a rise in temperature as shown in Figure 15 (Reference 19). Aging of concrete does not affect the magnitude of the specific heat but a loss of water from extreme drying may increase its value with time.

\subsection{EFFECT OF ELEVATED TEMPERATURE ON REINFORCING STEEL}

A temperature rise in concrete also influences the properties of the embedded reinforcing steel (Reference 21). Moreover, since the structural capacity of the waste storage tanks is a direct function of the strength and other mechanical properties of the steel reinforcement, an assessment of these properties at elevated temperatures is required. Like concrete, the yield strength and modulus of elasticity of the steel will reduce with increasing temperatures. However, the reduction is not as detrimental as in the concrete. This section summarizes the available data in the temperature range of interest on this topic.

\section{1 yield strength}

Up to a temperature of about $371^{\circ} \mathrm{C}\left(700^{\circ} \mathrm{F}\right)$, experiments have shown that hot-rolled reinforcement steels show a linear decrease in yield strength amounting to a maximum value of $15 \%$ (Reference 21). More pronounced reductions are observed at higher temperatures. In the same temperature range, ambient to $371^{\circ} \mathrm{C}$ $\left(700^{\circ} \mathrm{F}\right)$, the reduction in cold twisted and cold drawn steels can reach $20 \%$ (Reference 27 ). 


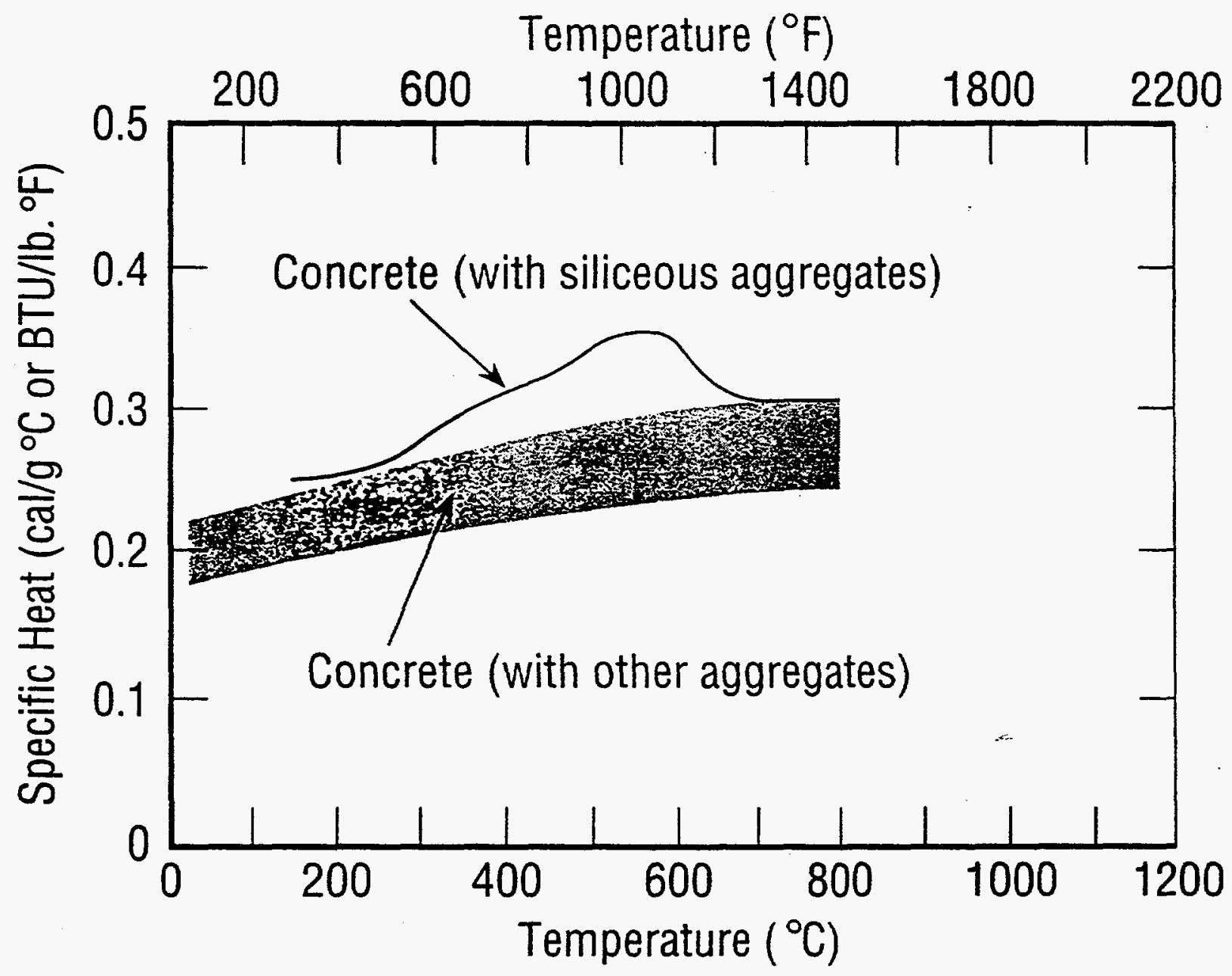

Figure 15 Variation of Specific Heat with Temperature 


\subsection{Kedulus of Flasticity}

The modulus of elasticity of reinforcing steel decreases linearly with increasing temperature as shown in Figure 16 (Reference 27). Up to a temperature level of $572^{\circ} \mathrm{F}\left(300^{\circ} \mathrm{C}\right)$, the mean residual modulus of elasticity is about $85 \%$ of its room temperature value.

\section{3 coefficient of Thermal Expansion}

The coefficient of thermal expansion of reinforcing steel (low alloy steel) increases linearly with a rise in temperature. In the range of temperatures of interest, however, the increase is insignificant and may be neglected (Reference 27).

\subsection{Thermal conductivity and Thermal Diffusivity}

As the temperature increases, thermal conductivity and thermal diffusivity of reinforcing steel (low alloy steel) decrease. Note that the opposite holds for high alloy austenitic steel. Here, again, in the temperature range of interest, ambient to $371^{\circ} \mathrm{C}$ $\left(700^{\circ} \mathrm{F}\right)$, insignificant variations in these properties are observed for both low carbon and high alloy steels (Reference 27).

\subsection{BOND STRENGTH}

Since concrete and reinforcing steel have different coefficients of thermal expansion, the bond strength and consequently the structural behavior could be influenced by a rise in temperature. Experimental data to determine the bond strength of concrete subjected to elevated temperature have been reported in References $13,46,47$ and 48 .

In Reference 13, concrete specimens cast from standard cement, silica aggregate, and a water to cement ratio of 0.5 were subjected to elevated temperatures up to $450^{\circ} \mathrm{C}\left(842^{\circ} \mathrm{F}\right)$. At each designated level, the temperature was kept constant for 72 hours after which gradual cooling was allowed for 48 hours, and the specimens were then tested to determine the strength which caused a specified slippage of $0.050 \mathrm{~mm}$ of the free end of the reinforcing steel. The test results are plotted in Figure 17 as residual strength ratios, i.e., the ratio of a specimen's bond strength determined in the test to the bond strength of a non-heated specimen cured under identical conditions. For example, at $100^{\circ} \mathrm{C}\left(212^{\circ} \mathrm{F}\right)$ the residual bond strength is $60 \%$ while at $300^{\circ} \mathrm{C}\left(572^{\circ} \mathrm{F}\right)$ it is about $55 \%$. Results presented in References 46 and 47 indicate that for exposure to temperatures in the range from ambient to $150^{\circ} \mathrm{C}\left(302^{\circ} \mathrm{F}\right)$ and under controlled laboratory conditions, the loss in bond strength between the concrete and reinforcement steel amounts to less than 15\%. However, other limited data indicate that the residual bond strength is only 50\% after subjecting the specimens (made from river gravel concrete with plain round steel bars) to $300^{\circ} \mathrm{C}\left(572^{\circ} \mathrm{F}\right)$ for 90 days and then cooling to room temperature 


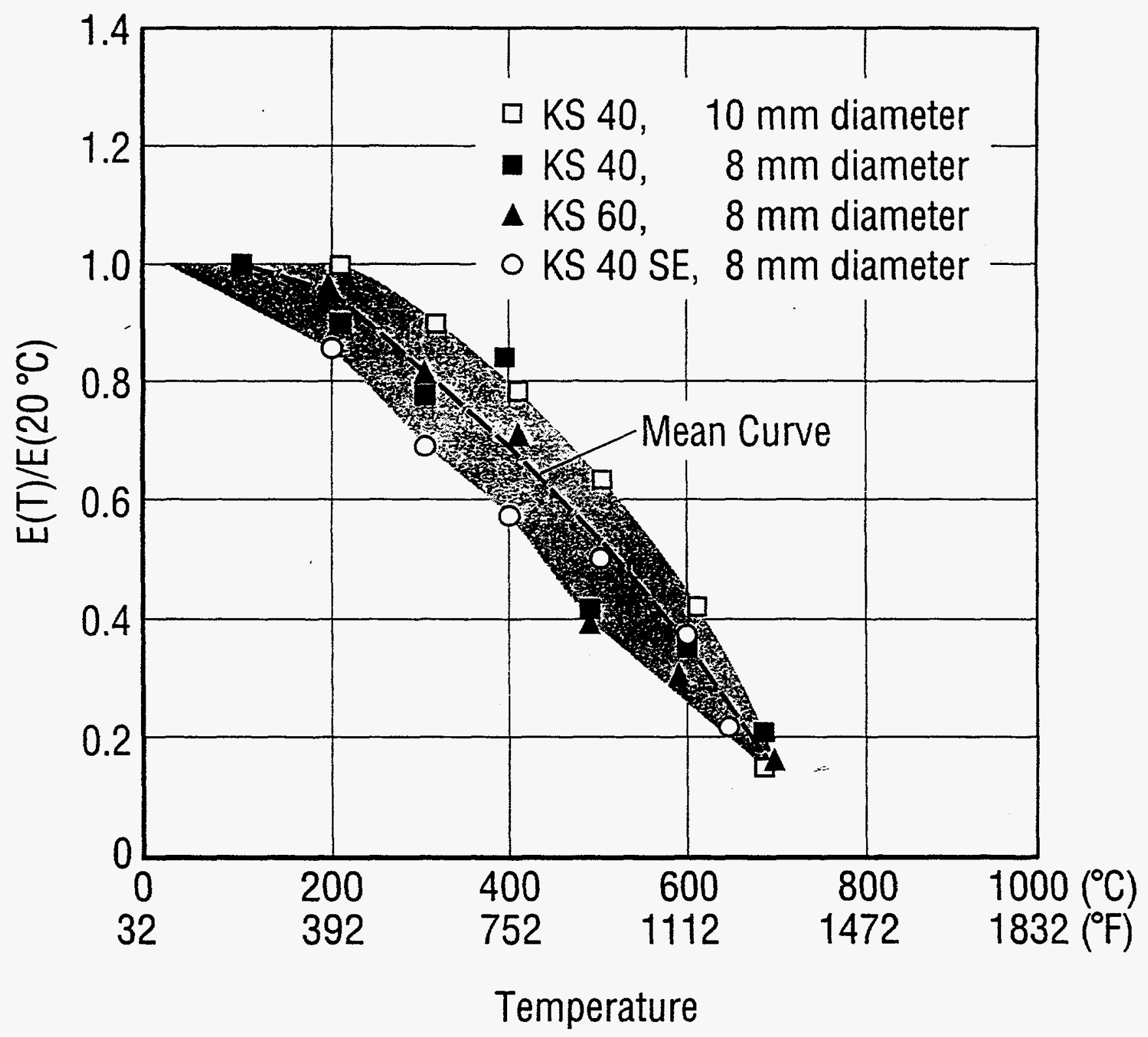

Figure 16 Influence of Temperature on Modulus of Elasticity of
Different Reinforcing steels 


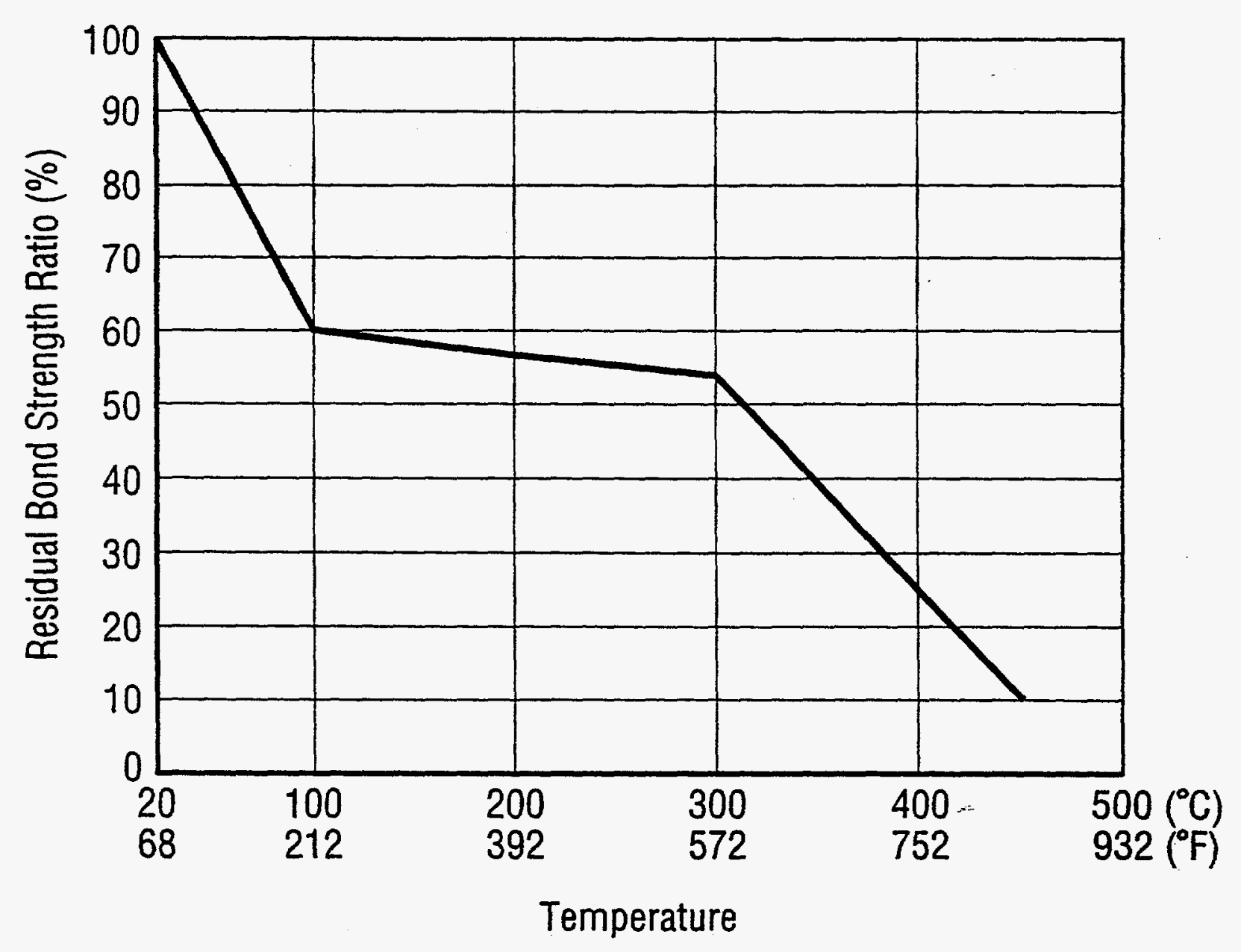

Figure 17 Bond Strength of Concrete at $0.050 \mathrm{~mm}(0.002 \mathrm{in.})$ slippage of Free End 
before testing (Reference 48). Ribbed and deformed bars obviously experience less loss in resistance to pull out than plain bars.

\subsection{THERMAL CYCLING}

Thermal cycling causes progressive degradation of concrete. Usually it affects the compressive strength more than the modulus of elasticity. With an increasing number of cycles though most of the damage occurs in the first few cycles. The influence of thermal cycling on the mechanical properties of concrete has been investigated in References $3,6,18,33$, and others. Reference 3 indicates that cyclic heating generally causes greater reduction in mechanical properties than a single heating even at a relatively moderate temperature rise of $65^{\circ} \mathrm{C}\left(149^{\circ} \mathrm{F}\right)$. In Reference 6,20 thermal cycles were applied with maximum temperatures selected as $65^{\circ} \mathrm{C}\left(149^{\circ} \mathrm{F}\right), 200^{\circ} \mathrm{C}\left(392^{\circ} \mathrm{F}\right)$, and $300^{\circ} \mathrm{C}\left(572^{\circ} \mathrm{F}\right)$. Three different aggregates were used in the test program, namely, lightweight expanded shale, fireclay brick, and pure limestone. The specimens were unsealed and the temperature cycles were performed in a laboratory oven with mechanical ventilation. Progressive deterioration of the mechanical characteristics with an increasing number of cycles was observed. At higher temperatures, 200 to $300^{\circ} \mathrm{C}\left(392\right.$ to $572^{\circ} \mathrm{F}$ ), most of the damage is caused in the first few thermal cycles and is usually associated with a loss of bond between the aggregates and the matrix. The breakdown of bond between aggregates and mortar was least for fireclay brick aggregates and greatest for limestone aggregates. Figure 18 shows the effects of temperature cycles on concrete specimens made with limestone (Reference 6). At exposure to $300^{\circ} \mathrm{C}\left(572^{\circ} \mathrm{F}\right.$ ), a reduction of $40 \%$ in the compressive strength was observed after the first cycle and an insignificant further reduction occurred after 20 cycles.

Reference 18 reports the results of tests on sealed specimens cycled from 21 to 149 to $21^{\circ} \mathrm{C}\left(70\right.$ to 300 to $70^{\circ} \mathrm{F}$ ) for up to 14 cycles. The resulting stress vs. strain history is shown in Figure 19a. It is observed that, for 3 thermal cycles, the reductions in the compressive strength and modulus of elasticity are about 23 and 12 percent, respectively; for 14 cycles, the reductions are 48 and 38 percent. However, Reference 18 concludes that ". . . the duration at which the specimen is kept under $149^{\circ} \mathrm{C}\left(300^{\circ} \mathrm{F}\right)$ appears to be even a more important factor than the number of cycles." This can be illustrated from Figure $19 \mathrm{~b}$ by comparing the results of sustained exposure at $149^{\circ} \mathrm{C}\left(300^{\circ} \mathrm{F}\right)$ for 14 days and 25 days. Figure 20 illustrates the stress-strain relationships for 3 and 14 cycles applied to sealed limestone specimens (Reference 18) and tested at both $21^{\circ} \mathrm{C}\left(70^{\circ} \mathrm{F}\right)$ and $149^{\circ} \mathrm{C}\left(300^{\circ} \mathrm{F}\right)$. Reference 18 also investigated the effect of applying five thermal cycles of 21 to 149 to $21^{\circ} \mathrm{C}\left(70\right.$ to 300 to $\left.70^{\circ} \mathrm{F}\right)$ on specimens permitted to lose moisture during the thermal treatment and concluded that "there is little difference between the mechanical characteristics of the concrete when tested at $300^{\circ} \mathrm{F}$ or at $70^{\circ} \mathrm{F} . "$ Additional details may be found in Reference 33 for temperatures up to $71^{\circ} \mathrm{C}\left(160^{\circ} \mathrm{F}\right)$. 

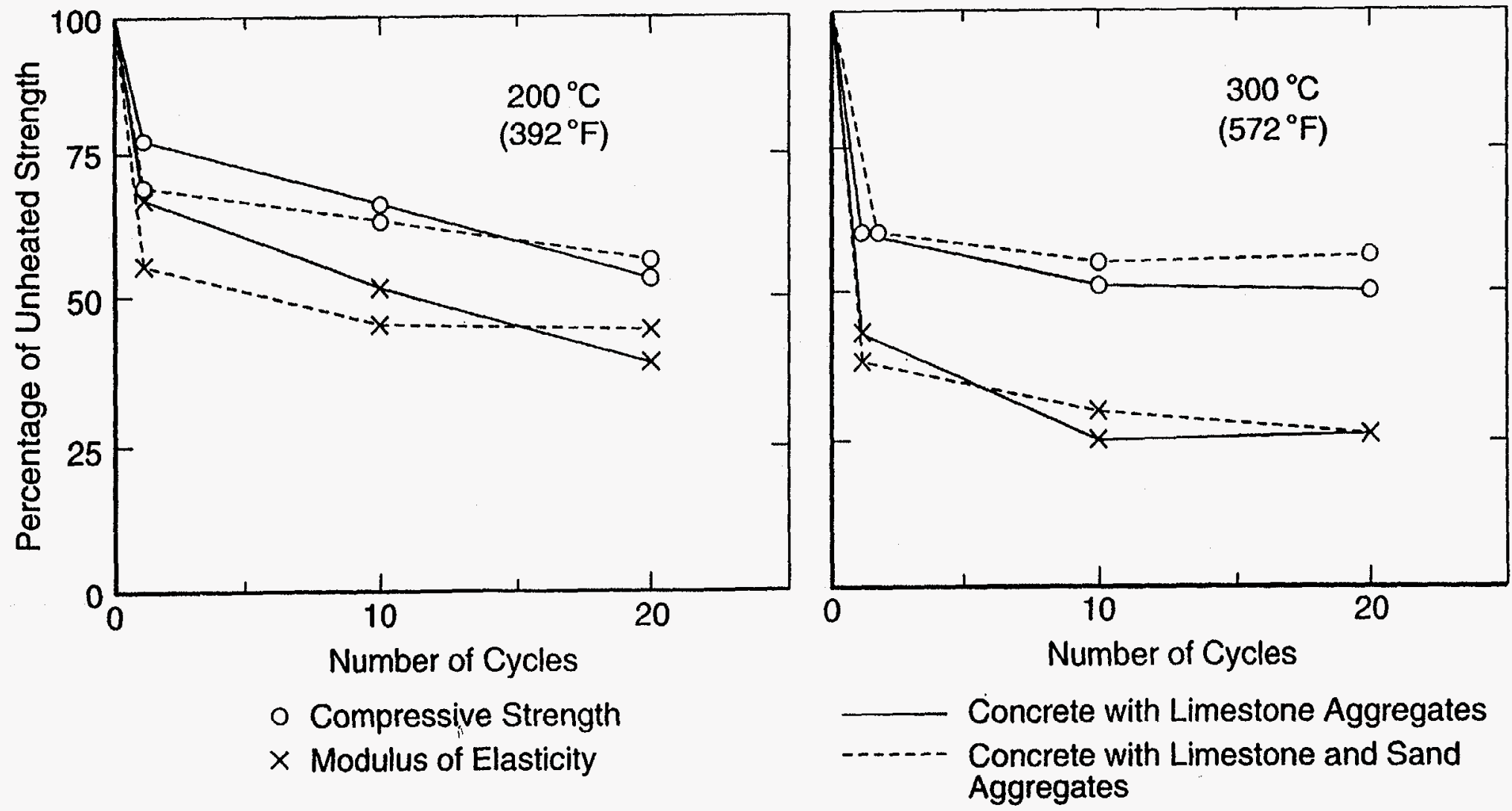

Figure 18 Effect of Thermal Cycling on Unsealed Limestone Concrete 

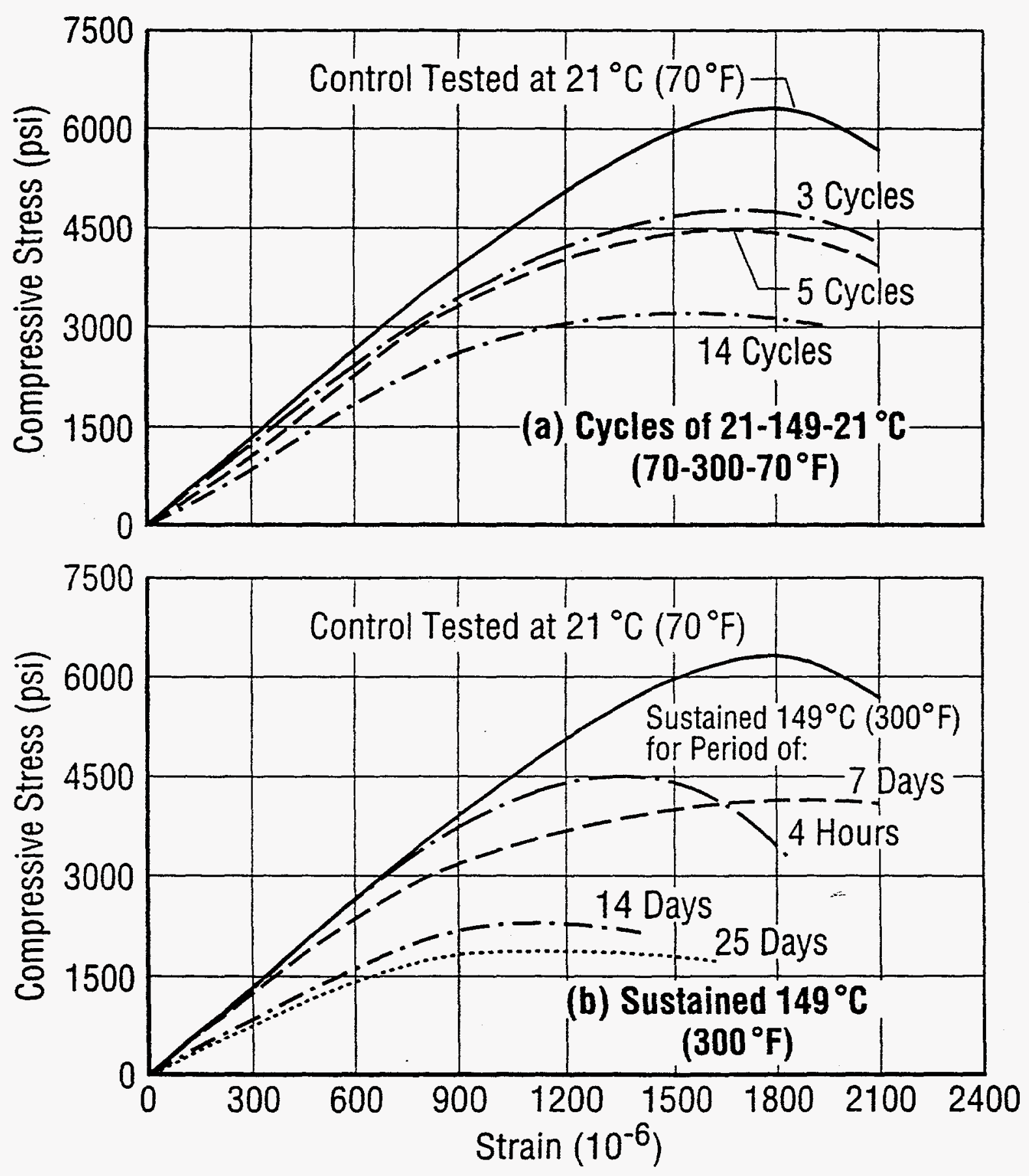

Figure 19 Effect of Thermal Cycling and Sustained Temperatures on sealed Iimestone concrete 


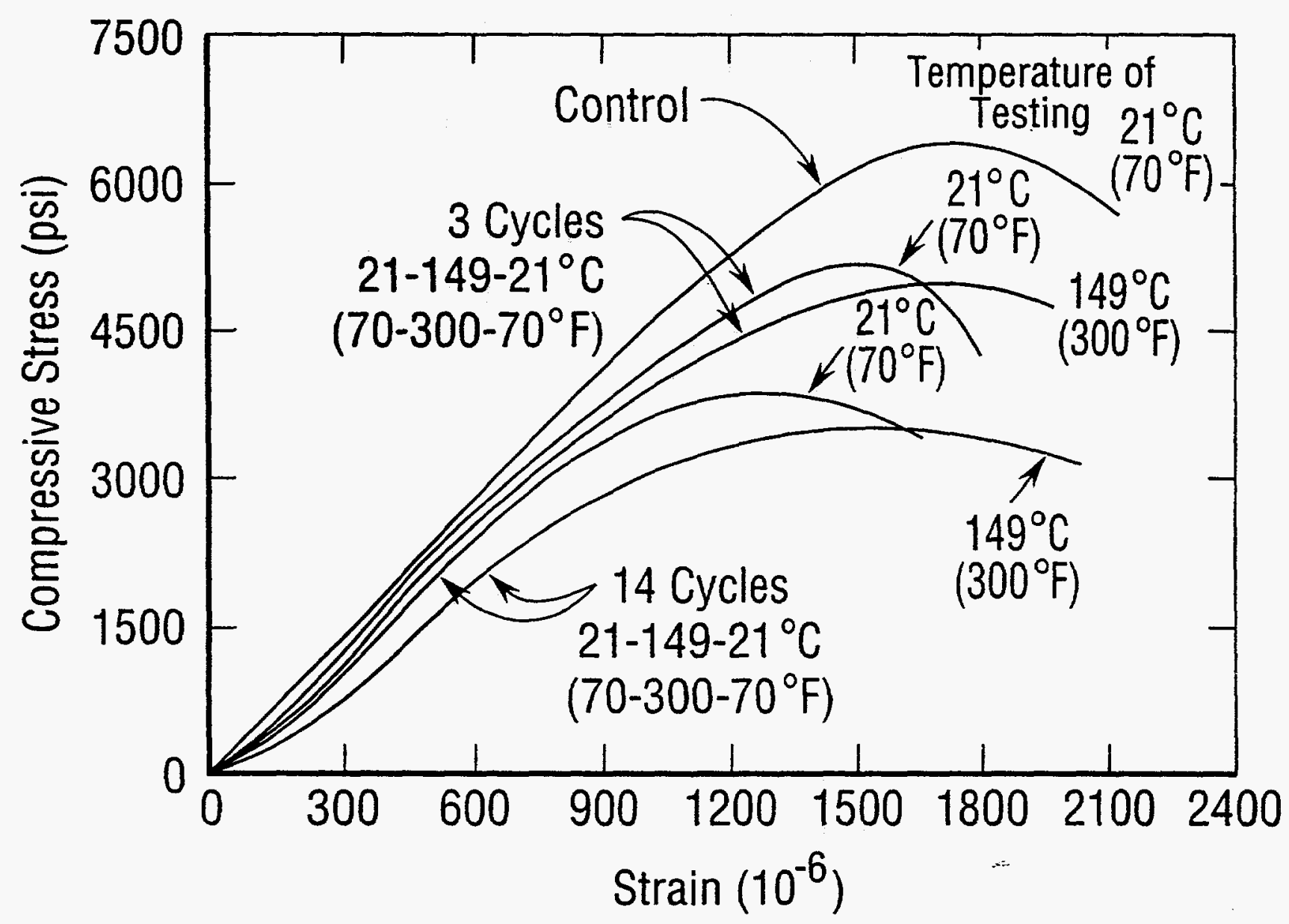

Figure 20 Effect of Thermal Cycling on Sealed Limestone Aggregate Concrete 


\subsection{EFFECT OF LONG-TERM EXPOSURE}

The effect of long-term exposure on the mechanical properties of concrete can be assessed from the test programs in References $11,33,49$ and 50. In these references, concrete specimens were maintained at elevated temperatures for long periods and then tested to determine the mechanical properties. A 5000-day exposure to $65^{\circ} \mathrm{C}\left(149^{\circ} \mathrm{F}\right)$ temperature increases the values of the compressive strength and modulus of elasticity of the concrete, making up for all of the loss in these properties due to the influence of elevated temperature (Reference 49). Similar results were found in Reference 33 for exposure to $71^{\circ} \mathrm{C}\left(160^{\circ} \mathrm{F}\right)$ for 270 days, and in Reference 11 for exposure to $121^{\circ} \mathrm{C}\left(250^{\circ} \mathrm{F}\right)$ for 200 days. At temperatures of $149^{\circ} \mathrm{C}\left(300^{\circ} \mathrm{F}\right)$ and higher, the increase in long-term exposure results in reduction in the mechanical properties (compressive strength and stiffness), and the rate of reduction increases with increasing temperature as shown in Figures 21 and 22 (Reference 11) and Figure 23 (Reference 50). It appears that most of the loss occurs during the early stages of exposure to elevated temperatures, i.e., within the first month. For example, at $300^{\circ} \mathrm{C}$ $\left(572^{\circ} \mathrm{F}\right)$, a residual compressive strength of about $65 \%$ is observed after two days and 50\% at the end of four months as shown in Figure 20. Similar behavior is observed in Figure 20 for the modulus of elasticity.

\subsection{SUMMARY}

An independent literature review has been performed to determine the influence of elevated temperatures from ambient to $315^{\circ} \mathrm{C}\left(600^{\circ} \mathrm{F}\right)$ on the behavior of concrete materials. The properties which control the behavior of concrete at elevated temperatures include the mechanical properties (compressive strength, tensile strength, and modulus of elasticity), timedependent properties (creep and shrinkage) and the thermal properties (coefficients of thermal expansion, conductivity, diffusivity and specific heat). Thermal cycling and long-term exposure to elevated temperatures as well as the influence of elevated temperatures on the steel reinforcement and bond strength are also investigated. The influence of elevated temperature on the creep of concrete is also examined. Since many variables and test conditions control the results in the data base, upper and lower bounds of the degraded properties at the elevated temperatures of interest are summarized and presented in explicit forms. The mean and $84 \%$ values are also presented based on the assumption that the distribution of the data is normal logarithmic. Such results are useful in assessing the effect of elevated temperatures on the structural behavior of the waste storage tanks. In addition, they provide the technical basis for assessing the structural integrity of these tanks when subjected to thermal excursions in addition to other operating loads. 


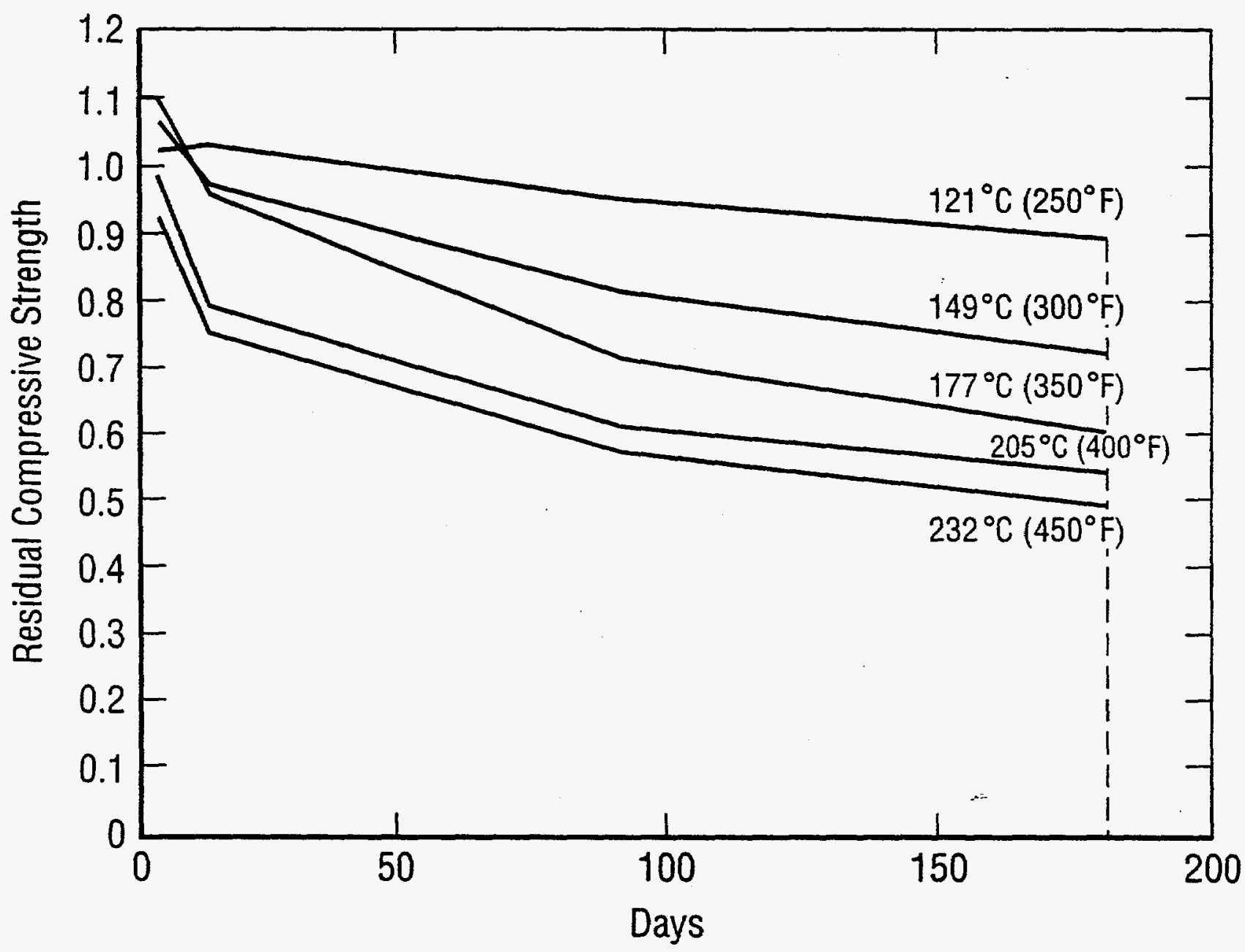

Figure 21 Variation of Residual Compressive strength with Temperature and Age 


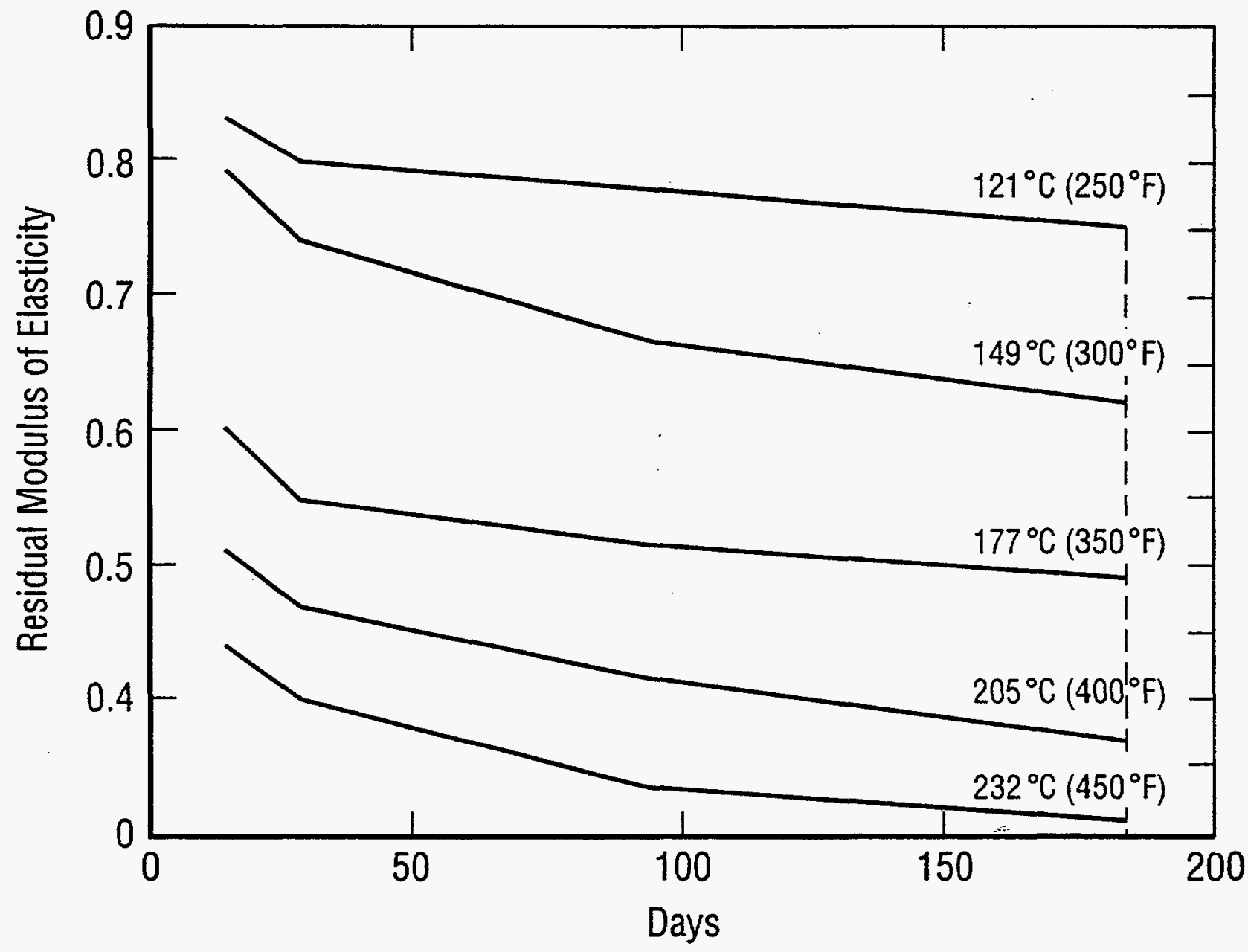

Figure 22 Variation of Modulus of Elasticity with Temperature and Age 


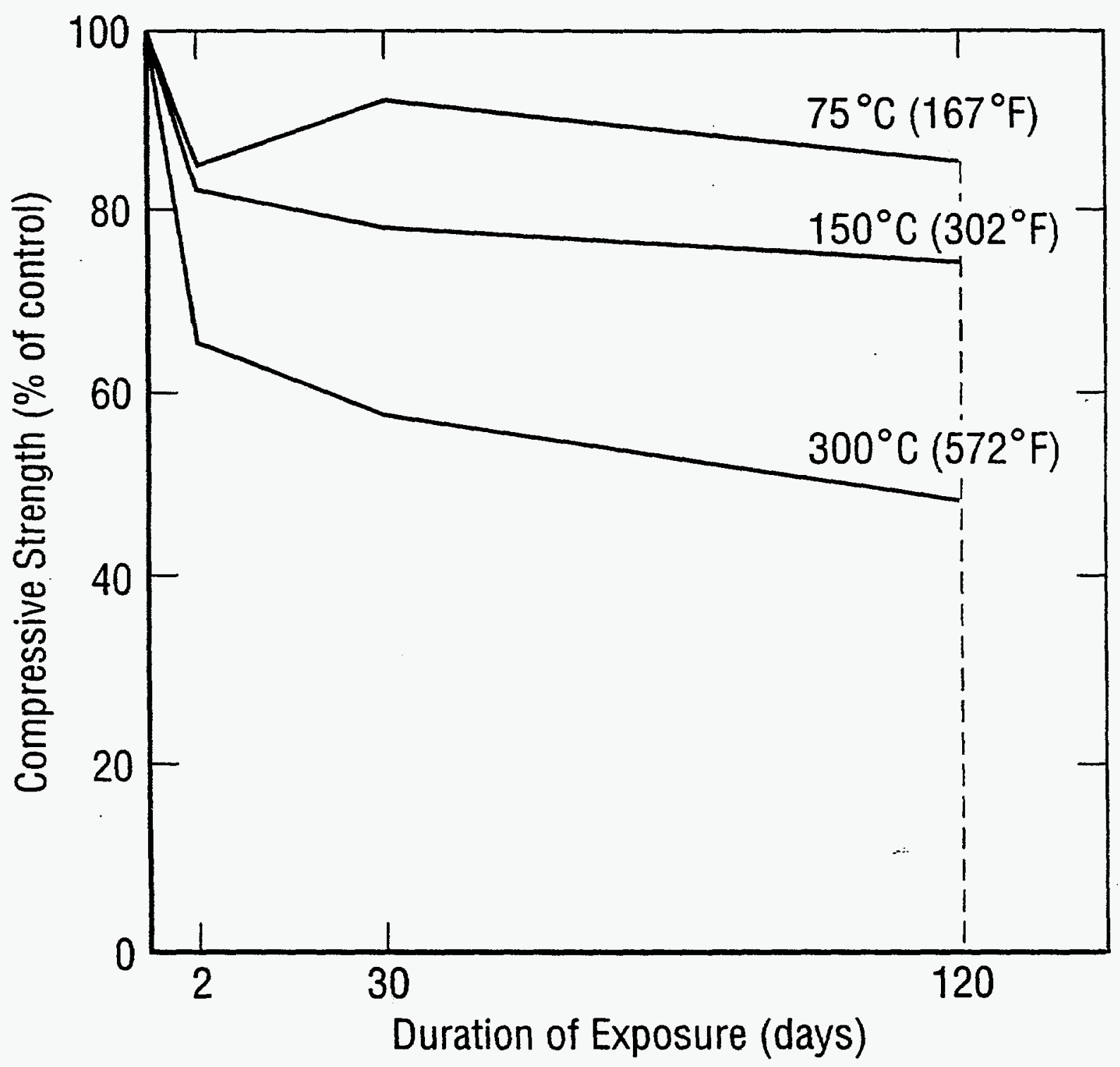

Figure 23 Effect of Duration of Exposure on Compressive strength of Limestone and Dolostone Concretes 


\subsection{REFERENCES}

1. Malhotra, H. L., "The Effect of Temperature on the Compressive Strength of Concrete," Magazine of Concrete Research, Volume 8 , No. 2, pp. 85-94, 1956.

2. Zoldners, N.G., "Effect of High Temperatures on Concrete Incorporating Different Aggregates," ASTM Proceedings, Volume 60 , pp. 1087-1108, 1960.

3. Campbell-Allen, D., Low, E.W.E. and H. Roper., "An Investigation on the Effect of Elevated Temperatures on Concrete for Reactor Vessels," Nuclear structural Engineering, Amsterdam, The Netherlands, Volume 1, Number 2, pp. 382-388, 1965.

4. Cruz, C.R., "Elastic Properties of Concrete at High Temperature," J. PCA. Research \& Development Laboratory, Volume 8, No. 1 (PCA Research Department Bulletin 191) pp. 3745,1966 .

5. Harmathy, T.Z. and Berndt, J.E., "Hydrated Portland Cement and Lightweight Concrete at Elevated Temperatures," Journal of American Concrete Institute, Proceedings, Volume 63, pp 93$112,1966$.

6. Campbell-Allen, D. and Desai, P.M., "The Influence of Aggregate on the Behavior of Concrete at Elevated Temperature," Nuclear Engineering and Design, Volume 6, No. 1, pp. $65-77,1967$.

7. Browne, R.D., "Properties of Concrete in Reactor Vessels," Conference on Prestressed Concrete Pressure Vessels at church House, Westminister, The Institute of Civil Engineers, London, Pager 13, pp. 131-151, March 1968.

8. Troxell, G.E., Davis, H.E. and Kelly, J.W., "Composition and Properties of Concrete," 2nd Edition, McGraw-Hill Book Co., New York, 1968.

9. Lankard, D. T., et al., "Effects of Moisture Content on the Structural Properties of Portland Cement Concrete Exposed to Temperatures Up to $500^{\circ} \mathrm{F}, "$ American Concrete Institute, SP-25, pp. 59-102, Detroit, Michigan, 1971.

10. Abrams, M. S., "Compressive strength of concrete at Temperatures to $1600^{\circ} \mathrm{F}$," American Concrete Institute, SP-26, pp. 33-58, Detroit, Michigan, 1971 .

11. Nasser, K. W. and Lohtia, R. P., "Mass Concrete Properties at High Temperatures," Journal of the American Concrete Institute, Proceedings, Volume 68, No. 3, pp. 180-186, 1971. 
12. Pihlajavaara, S. E., "An Analysis of the Factors Exerting Effect on Strength and other Properties of Concrete at Elevated Temperature," American Concrete Institute, SP-34, Volume I, Paper SP 34-19, pp. 347-354, Detroit, Michigan, 1972 .

13. Harada, T., Takeda, J., Yamane, S. and F. Furumura, "Strength, Elasticity and Thermal properties of concrete subjected to Elevated Temperatures," American Concrete Institute, SP-34, Volume I, pp. 377-406, Paper sP-34-21, Detroit, Michigan, 1972 .

14. Nishizawa, N. and H. Okamura, "strength and Inelastic Properties of concrete at Elevated Temperature," American Concrete Institute, SP-34, Volume I, pp. 407-421, paper SP-3422, Detriot, Michigan, 1972.

15. Crispino, E., "Studies on the Technology of Concretes Under Thermal Conditions," American Concrete Institute, SP-34, pp. 443-479, Paper SP-34-24, Detriot, Michigan, 1972.

16. Weigler, $H$. and R. Fischer, "Influence of High Temperatures on Strength and Deformation of Concrete," American Concrete Institute, SP-34, pp. 481-493, Paper SP-34-25, Detriot, Michigan, 1972 .

17. Marechal, J. C., "Variations in the Modulus of Elasticity and Poisson's Ratio with Temperature," American concrete Institute, SP-34, Volume I, Paper SP-34-27, pp. 495-504, Detroit, Michigan, 1972 .

18. Bertero, V.V. and M. Polivka, "Influence of Thermal Exposure on Mechanical Characteristics of Concrete," American concrete Institute, sp-34, pp. 505-531, Paper sp-34-28, Detroit, Michigan, 1972 .

19. Harmathy, T.Z. and Allen, L.W., "Thermal properties of Selected Masonry Unit Concrete," Journal of the American Concrete Institute, Proceedings, Volume 70, pp. 132-142, 1973.

20. American Concrete Institute, "Behavior of Concrete Under Temperature Extremes," Publication SP-39, 1973.

21. Smith, P., "Resistance to High Temperatures," in Significance of Test and Properties of concrete and Concrete-Making Materials, American Society for Testing and Materials STP 169B, Chapter 25, pp 388-419, Philadelphia, Pennsylvania, 1978 . 
22. Kottas, R., Seeberger, J. and H.K. Hilsdorf, "Strength Characteristics of Concrete in the Temperature Range of $20^{\circ} \mathrm{C}$ to $200^{\circ} \mathrm{C}$," Paper H1/2, Volume H, Session 1, Transaction of the 5 th International conference on structural Mechanics in Reactor Technology, Berlin, Germany, August 1979.

23. Nasser, K.W. and H.M. Marzouk, "Properties of Mass Concrete Containing Fly Ash at High Temperatures," Journal of the American Concrete Institute, Proceedings, Volume 76, pp. 537$550,1979$.

24. Oland, C.B., Naus, D.J. and Robinson, G.C., "Comprehensive Testing Program for Concrete at Elevated Temperature," Final Report, ORNL/BRP $80 / 5$, Oak Ridge National Laboratory, Oak Ridge, Tennessee, October 1980.

25. Fresakakis, G. N., "Behavior of Reinforced concrete at Elevated Temperature," Second ASCE Conference on Civil Engineering and Nuclear Power, Volume 1, Paper 3-4, Knoxville, Tennessee, September 1980.

26. Naus, D. J., "Concrete Properties in Nuclear Environment - A Review of Concrete Material systems for Application to Prestressed Concrete Pressure Vessels," ORNL/TM-7632, Oak Ridge National Laboratory, Oak Ridge, Tennessee, May 1981.

27. Schneider, U., Diederichs U., and C. Ehm, "Effect of Temperature on steel and concrete for PCRV's," Nuclear Engineering and Design, Volume 67, pp. 245-258, 1981.

28. Mindess, S. and J.F. Young, "Concrete," Prentice-Hall, Englewood Cliffs, New Jersey, 1981.

29. Naik, T.R. Editor, "Temperature Effects on Concrete," American Society for Testing and Materials, STP 858, American Society for Testing and Materials, Philadelphia, 1985.

30 Naus, D. J., "A Review of the Effects of Elevated Temperature on Concrete Materials and Components with Particular Reference to the Modular High-Temperature Gas-Cooled Reactor (MHTGR)," ORNL/NRC/LTR-88/2, LTR Report CTP-88-01, Concrete Technology Program, Oak Ridge National Laboratory, Oak Ridge, Tennessee, March 1988.

31. Omatsuzawa, K., et al., "Behavior and Ultimate strength of an Inner Concrete structure of a Nuclear Reactor Building Subjected to Thermal and Seismic Loads," Structural Mechanics in Reactor Technology, wittmann, F.H., Editor, Volume J, Extreme Loading and Response of Reactor Containments, pp. 167172 , August 1987. 
32. Takeda, T., Nakane, S. and K. Nagao, "Experimental Studies on Characteristics of Concrete Members subjected to High Temperature," structural Mechanics in Reactor Technology, Wittmann, F.H., Editor, Volume H, Concrete and concrete Structures, pp. 195-200, August 1987.

33. Komendant, J., Nicolayeff, V., Polivka, M. and D. Pirtz, "Effect of Temperature, Stress Level, and Age at Loading on Creep of Sealed Concrete," Douglas McHenry International Symposium on Concrete and concrete structures, American Concrete Institute, publication SP-55, pp. 55-81, Detriot, Michigan, 1978 .

34. Neville, A.M., "Creep of Concrete: Plain, Reinforced and Prestressed," North Holland Publishing Co., Amsterdam, The Netherlands, 1970.

35. Nasser, K., and A.M. Neville, "Creep of Concrete at Elevated Temperatures," ACI Journal, Proceedings, Volume 62, pp. 15671579, Detroit, Michigan, 1965.

36. Nasser, K., and A.M. Neville, "Creep of old Concrete at Normal and Elevated Temperatures," ACI Journal, Proceedings, Volume 64, pp. 97-103, Detroit, Michigan, 1967.

37. Hannant, D.J., "Strain Behavior of Concrete Up to $95^{\circ} \mathrm{C}$ Under Compressive stresses," Conference on Prestressed concrete Pressure Vessels at Church House, Westminster, The Institute of Civil Engineers, pp. 177-192, London, England, 1968.

38. Nasser, K.W., and Lohtia, R.P., "Creep of Mass Concrete at High Temperatures," Journal of the American Concrete Institute Proceedings, pp. 276-281, Detroit, Michigan, 1971.

39. Geymayer, H.G., "Effect of Temperature on creep of Concrete: A Literature Review," American Concrete Institute, SP-34, Paper SP 34-31, pp. 565-589, Detroit, Michigan, 1972.

40. McDonald, J.E., "An Experimental Study of Multiaxial Creep in Concrete," American Concrete Institute, SP-34, Volume II, Paper SP-34-36, pp. 735-768, Detroit, Michigan, 1972.

41. Gross, H., "High Temperature Creep of Concrete," Nuclear Engineering and Design, Volume 32, pp. 129-147, 1975.

42. McDonald, J.E., "Creep of Concrete Under Various Temperature, Moisture, and Loading Conditions," Douglas McHenry International symposium on concrete and concrete structures, American Concrete Institute, Publication SP-55, pp. 31-53, 1978 . 
43. Nasser, K.W., and H.M. Marzouk, "Creep of Concrete at Temperatures from 70 to $450^{\circ} \mathrm{F}$ Under Atmospheric Pressure," Journal of the American Concrete Institute, Proceedings, Volume 78, pp. 147-150, 1981.

44. Daye, M.A., "Creep of Concrete for Reactor/Containment Buildings," American Concrete Institute, SP-76, pp. 142-168, American Concrete Institute, Detroit, Michigan, 1982.

45. American Concrete Institute, "Prediction of Creep, Shrinkage and Temperature Effects in Concrete structure," ACI 209R-92, American Concrete Institute Manual of Concrete Practice, Part 1, Detroit, Michigan, 1993.

46. Oland, C. B. and Callahan, J.P., "Bond Between concrete and steel Reinforcement at Temperatures to $149^{\circ} \mathrm{C}\left(300^{\circ} \mathrm{F}\right), "$ ORNL/TM-6086, Union Carbide Corp., Nuclear Division, Oak Ridge National Laboratory, Oak Ridge, Tennessee, 1978.

47. Diederichs, U. and Schneider, U., "Bond Strength at High Temperatures," Magazine of Concrete Research, Volume 35, No. 115, pp. 75-84, 1981 .

48. Kagami, H., et al., "Properties of Concrete Exposed to Sustained Elevated Temperatures," 3rd International Conference on structural Mechanics in Reactor Technology, paper H1/5, London, 1975.

49. Mears, A.P., "Long Term Tests on the Effect of Moderate Heating on the Compressive Strength and Dynamic Modulus of Elasticity of Concrete," American Concrete Institute, SP-34, Volume I, pp. 355-375, Detroit, Michigan, 1972.

50. Carette, G.G. and V. Mohan Malhotra, "Performance of Dolostone and Limestone Concretes at sustained High Temperatures," Temperatures Effects on Concrete, American Society for Testing and Materials, STP 858, T.R. Naik, Ed., pp. 38-67, 1985. 